\title{
OPEN Overexpression of wild-type human amyloid precursor protein alters GABAergic transmission
}

\author{
Anna Kreis ${ }^{1}$, Jana Desloovere ${ }^{2}$, Nuria Suelves ${ }^{3}$, Nathalie Pierrot ${ }^{3}$, Xavier Yerna ${ }^{1}$, \\ Farah Issa ${ }^{1}$, Olivier Schakman ${ }^{1}$, Roberta Gualdani ${ }^{1}$, Marie de Clippele ${ }^{1}$, Nicolas Tajeddine ${ }^{1}$, \\ Pascal Kienlen-Campard ${ }^{3}$, Robrecht Raedt ${ }^{2}$, Jean-Noël Octave ${ }^{3}$ \& Philippe Gailly ${ }^{1 凶}$
}

The function of the amyloid precursor protein (APP) is not fully understood, but its cleavage product amyloid beta $(A \beta)$ together with neurofibrillary tangles constitute the hallmarks of Alzheimer's disease (AD). Yet, imbalance of excitatory and inhibitory neurotransmission accompanied by loss of synaptic functions, has been reported much earlier and independent of any detectable pathological markers. Recently, soluble APP fragments have been shown to bind to presynaptic GABA ${ }_{B}$ receptors $\left(G A B A_{B} R s\right)$, subsequently decreasing the probability of neurotransmitter release. In this body of work, we were able to show that overexpression of wild-type human APP in mice (hAPP $\left.{ }_{\text {wt }}\right)$ causes early cognitive impairment, neuronal loss, and electrophysiological abnormalities in the absence of amyloid plaques and at very low levels of $A \beta$. hAPP $_{w t}$ mice exhibited neuronal overexcitation that was evident in EEG and increased long-term potentiation (LTP). Overexpression of hAPP ${ }_{\text {wt }}$ did not alter GABAergic/glutamatergic receptor components or GABA production ability. Nonetheless, we detected a decrease of GABA but not glutamate that could be linked to soluble APP fragments, acting on presynaptic $G_{A B A} R$ s and subsequently reducing $G A B A$ release. By using a specific presynaptic $\mathrm{GABA}_{\mathrm{B}} \mathrm{R}$ antagonist, we were able to rescue hyperexcitation in $h A P P_{w t}$ animals. Our results provide evidence that APP plays a crucial role in regulating inhibitory neurotransmission.

The amyloid precursor protein (APP) is a single-pass transmembrane protein that is highly conserved in the animal kingdom. In humans, the $A P P$ gene is located on chromosome 21 and its alternative splicing results in three isoforms containing 695, 751 and 770 amino acids, with $\mathrm{APP}_{695}$ being predominantly expressed in neurons $s^{1,2}$. The physiological function of APP is not fully understood but its metabolism, as a precursor of amyloid $\beta$ peptides $(A \beta)$, plays a central role in initiating Alzheimer's disease (AD). APP can be processed in two major pathways: the amyloidogenic and non-amyloidogenic, generating biologically active fragments with different functions. Amyloidogenic processing of APP by $\beta$-site APP cleaving enzyme (BACE1) with subsequent cleavage by presenilin-containing $\gamma$-secretase, liberates soluble APP beta (sAPP $\beta$ ) and A $\beta^{3}$. A $\beta$ monomers can further aggregate into soluble oligomers, protofibrils and large insoluble amyloid fibrils that further assemble into amyloid plaques, promoting neurodegeneration constituting a key step in the pathophysiology of $\mathrm{AD}^{4}$. In the non-amyloidogenic pathway, APP cleavage by a-secretase (ADAM10) yields soluble APP alpha (sAPPa) preventing the production of $A \beta^{5}$. Over the years, $A \beta$ plaque deposition and the resulting neuronal loss due to the amyloid cascade was the focal point in $\mathrm{AD}$ research. However, despite the evidence suggesting a causal role of $\mathrm{A} \beta$ in $\mathrm{AD}$, including disease-generating APP mutations, it has been shown early on that synaptic function is affected at the earliest stages of $\mathrm{AD}$ and partially independently from the formation of $\mathrm{A} \beta$ plaques ${ }^{6,7}$. Moreover, clinical trials using BACE1 or $\gamma$-secretase inhibitors to reduce $A \beta$ formation or anti-A $\beta$ antibodies in order to minimize amyloid deposits in AD patients, have been unsuccessful thus far ${ }^{8-10}$. The lack of treatment success of some $A \beta$-centered medications might be due to the residual presence of $A \beta$ oligomers. Promising strides in $A \beta$ plaque treatment have been made by aducanumab, although its efficacy is still under discussion ${ }^{11,12}$. The function of $\mathrm{A} \beta$ in $\mathrm{AD}$ becomes even more complex when considering that the binding of $\mathrm{A} \beta$ oligomers to synapses and their adverse consequences require the presence of $\mathrm{APP}^{13}$. Another disease associated with APP is the Down syndrome (DS). Individuals with DS carry three copies of chromosome 21 resulting in triplication of

\footnotetext{
${ }^{1}$ Laboratory of Cell Physiology, Institute of Neuroscience, Université Catholique de Louvain, av. Mounier 53/B1.53.17, 1200 Brussels, Belgium. ' Faculty of Medicine and Health Sciences, Universiteit Gent, C. Heymanslaan 10, 9000 Gent, Belgium. ${ }^{3}$ Alzheimer Dementia Group, Institute of Neuroscience, Université Catholique de Louvain, av. Mounier 53, 1200 Brussels, Belgium. ${ }^{\square}$ email: philippe.gailly@uclouvain.be
} 
dosage-sensitive genes that greatly enhance the risk for AD in DS individuals. AD and DS, both neurodegenerative diseases with a common neuropathological basis, have been associated with seizure activity and epilepsy in human subjects ${ }^{14}$ as well as increased excitatory transmission in animal models ${ }^{15,16}$. The partial overlap in the neuropathology of $\mathrm{AD}$ and $\mathrm{DS}$ suggests that some common pathogenic mechanisms may exist and are related to APP, which is known to regulate the balance between excitatory and inhibitory neurotransmission. Interestingly, it has been shown that APP overexpression, and not the resulting overproduction of $A \beta$, is responsible for EEG abnormalities such as network hyperexcitability and epileptiform spikes in APP overexpressing mice ${ }^{17,18}$. APP has been associated with neuronal proliferation and differentiation ${ }^{19,20}$ and plays a role in neurite outgrowth as well as synapse formation ${ }^{21,22}$. The manner in which APP affects neurotransmission is a complex question. APP is abundantly expressed in presynaptic boutons where it is a key partner of multiple presynaptic proteins ${ }^{23}$, and its cleavage products affect both excitator $y^{24,25}$ and inhibitory ${ }^{26,27}$ synaptic transmission. Glutamate is the main excitatory neurotransmitter in the CNS that contributes to memory, learning, and synaptic plasticity ${ }^{28,29}$. Glutamate exerts its excitatory function via the N-methyl-D-aspartate receptor (NMDAR) and a-amino-3-hydroxy5-methyl-4-isoxazolepropionic acid receptor (AMPAR). APP plays a role in NMDAR trafficking, enhancing its surface expression in the process ${ }^{30,31}$ while NMDAR activation decreases surface expression of APP, promoting amyloidogenesis $^{32}$. In mice, overexpressing wild-type APP or APP with a Swedish double mutation, similar to cases of early-onset Alzheimer's disease (EOAD) in humans, the expression and function of the AMPAR was reduced in neurons ${ }^{33}$. On the other hand, Gamma-aminobutyric acid (GABA) is the main inhibitory neurotransmitter in the brain operating through fast acting ionotropic GABA type $A$ receptors $\left(G_{A B A} R s\right)$ and slow metabotropic GABA type $B$ receptors $\left(\mathrm{GABA}_{B} \mathrm{Rs}\right)$. $\mathrm{GABA}_{A} \mathrm{Rs}$ allow the bidirectional transport of $\mathrm{Cl}^{-}$ions and $\mathrm{GABA}_{\mathrm{A}} \mathrm{R}$-mediated responses depend mainly on the cross-membrane $\mathrm{Cl}^{-}$gradient which itself is determined by the intracellular $\mathrm{Cl}^{-}$concentration $\left(\left[\mathrm{Cl}^{-}\right]_{\mathrm{i}}\right.$ ). Cation-chloride transporters are considered to play a crucial role in $\mathrm{Cl}^{-}$homeostasis. Under normal conditions the $\mathrm{K}^{+}-\mathrm{Cl}^{-}$cotransporter $\mathrm{KCC} 2$ extrudes $\mathrm{Cl}^{-}$from the cell while the $\mathrm{Na}^{+}-\mathrm{K}^{+}-2 \mathrm{Cl}^{-}$cotransporter NKCC1 promotes the intracellular accumulation of $\mathrm{Cl}^{-34,35}$. Imbalance in the expression or in the function of KCC2 or NKCC1 can lead to disrupted GABAergic inhibition. During neuronal maturation, expression of NKCC1 and KCC2 progressively decreases and increases, respectively. This change in expression induces a shift in GABAergic signaling from excitatory to inhibitory, also known as the GABA shift ${ }^{36}$. Not long ago, we demonstrated that the overexpression of APP in cortical cell cultures affects the GABA shift by decreasing KCC2 expression, without modifying NKCC1, resulting in a diminished inhibitory GABA response ${ }^{37}$. However, APP also seems to directly interact with $\mathrm{KCC} 2$, ensuring its stability and function at the cell surface ${ }^{38}$. GABA $\mathrm{B}$ s are composed of two subunits $\mathrm{GABA}_{\mathrm{B} 1}$ and $\mathrm{GABA}_{\mathrm{B} 2}$. The $\mathrm{GABA}_{\mathrm{B} 1}$ subunit is further divided in two isoforms $\mathrm{GABA}_{\mathrm{B} 1 \mathrm{a}}$ and $\mathrm{GABA}_{\mathrm{B} 1 \mathrm{~b}}$ which differ in the presence of a tandem pair of extracellular domains, called sushi domain, located at the $\mathrm{GABA}_{\mathrm{B} 1 \mathrm{a}}$ isoform ${ }^{39}$. Interestingly, APP is highly expressed in GABAergic interneurons ${ }^{40}$ and was found to be part of the $\mathrm{GABA}_{B} \mathrm{R}$ complex ${ }^{41}$. Binding of APP to $\mathrm{GABA}_{\mathrm{B}} \mathrm{Rs}$ promotes axonal trafficking, cell-surface expression of $G_{A B A} R s$, presynaptic inhibition, and at the same time protects APP from amyloidogenic cleavage by BACE $1^{42}$. Compelling results published by Rice and colleagues revealed an additional function of APP concerning neurotransmission. Soluble APP, a product of both proteolytic cleavage pathways, was shown to bind to presynaptic $\mathrm{GABA}_{\mathrm{B}} \mathrm{Rs}$ and regulate presynaptic neurotransmitter release $\mathrm{e}^{43}$.

To investigate the role of APP in GABAergic signaling independent of A $\beta$ plaques and APP mutations, we used a mouse model developed by Mucke and colleagues, that overexpresses wild-type human APP (hAPP wt $_{\text {ine }}$ I5) under the PDGF promoter, resulting in moderately (3-fourfold) increased levels of APP but with very low levels of $\mathrm{A} \beta$ peptides and no amyloid plaque formation ${ }^{18,44}$. In this study, we further characterized the $\mathrm{hAPP}_{\mathrm{wt}}$ mouse model using behavioral experiments, with a focus on learning and memory as well as electrophysiology and report cognitive impairment, anxiety, and aberrant excitatory signaling in the hippocampus of $\mathrm{hAPP}_{\mathrm{wt}}$ mice. We did not register any major changes in the expression of excitatory or inhibitory receptors or proteins involved in GABA production or efficacy. Further probing revealed changes in GABA content but not glutamate indicating diminished GABA function caused by APP overexpression.

\section{Results}

Characterization of APP metabolism in hAPP ${ }_{\text {wt }}$ mice. We first confirmed the expression of human wild-type APP in 6 month old hAPP ${ }_{\text {wt }}$ with no detection in control samples (Fig. 1a). Using the APP C-terminus antibody recognizing both human and endogenous mouse APP (Sigma Aldrich), we measured the expression of total APP which was increased by four times in $\mathrm{hAPP}_{w t}$ mice compared to controls $(\mathrm{P}=0.0018$; Fig. 1a). Soluble endogenous mouse and human APP protein levels were determined using the anti-APP N-terminus clone 22C11 antibody (Merck). Analysis of media taken from organotypic brain slice cultures of 6 month old male hAPP ${ }_{w t}$ and control animals revealed a significant increase $(\mathrm{P}=0.0447)$ in soluble mouse and human APP fragments in $\mathrm{hAPP}_{\mathrm{wt}}$ animals compared to controls (Fig. 1b). Soluble APP fragments are generated in both APP cleavage pathways with sAPPa resulting from non-amyloidogenic cleavage and SAPP $\beta$ being the product of amyloidogenic processing. When comparing these two peptides, sAPP $\alpha$ is generally associated with beneficial functions and a possible therapeutic strategy for AD treatment, while sAPP $\beta$ is thought to have no positive functions at all $^{45}$. Remarkably, both sAPP forms play a role in the regulation of presynaptic neurotransmitter release ${ }^{43}$. Since the discrimination of different sAPP species via western blot is rather difficult we set out to determine the human SAPP concentrations of both sAPP $\alpha$ and sAPP $\beta$ using an ECLIA assay (Mesoscale). Calculated levels of $\mathrm{sAPPa} / \mathrm{sAPP} \beta$ were normalized to protein amount of hippocampal samples taken from 6 month old male hAPP ${ }_{w t}$ mice and age-matched controls. We detected significantly more $(\mathrm{P}=0.0009)$ sAPPa compared to sAPP $\beta$ with no detectable levels of human sAPP fragments in control samples (Fig. 1c). We additionally measured hippocampal levels of $A \beta_{40}$ and $A \beta_{42}$ at 6 months of age using an ECLIA assay (Mesoscale) specific for human $A \beta$ peptides. $h A P P_{w t}$ mice had almost non-detectable levels of $A \beta_{42}(P \leq 0.0001)$ and low amount of 
a

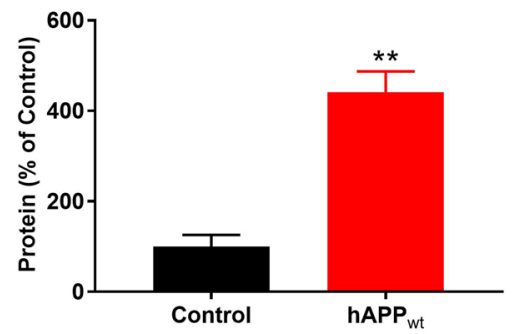

b

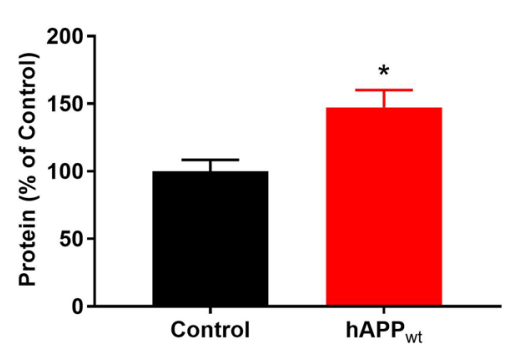

C

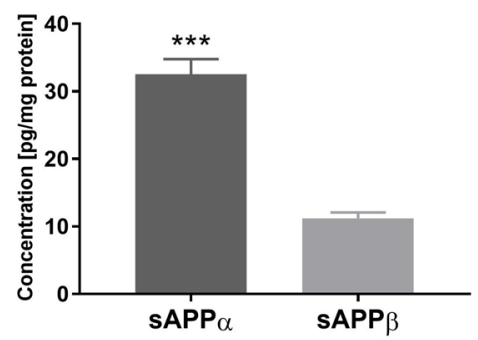

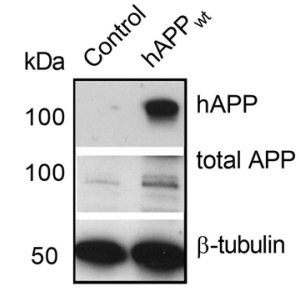

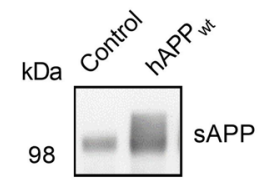

d

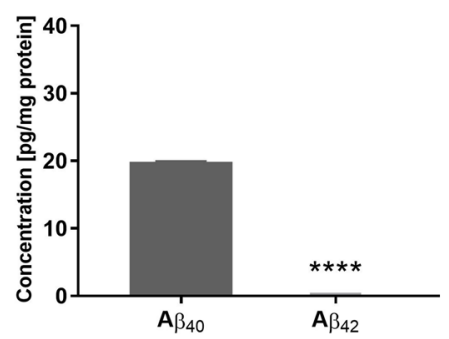

Figure 1. Characterization of APP metabolism in 6 month old male hAPP ${ }_{w t}$ mice and control littermates. (a) Quantification of total (mouse and human) APP (left panel) and representative western blots of human APP (hAPP) and total APP in hippocampal tissue lysates of 6 month old hAPP $\mathrm{wt}_{\mathrm{w}}(\mathrm{n}=4)$ and control $(\mathrm{n}=4)$ animals (protein amount was normalized to $\beta$-tubulin and expressed as percentage). (b) Quantification and representative western blot of soluble mouse and human APP measured in medium collected from organotypic brain slice cultures of 6 months old hAPP $(n=3)$ and control $(n=3)$ animals (protein amount was normalized to controls and expressed as percentage). (c) Quantitative determination of soluble human APP (sAPP $\alpha / \mathrm{sAPP} \beta)$ and $(\mathbf{d})$ human amyloid peptides $\left(\mathrm{A} \beta_{40} / \mathrm{A} \beta_{42}\right)$ in hippocampal tissue lysates of 6 month old male hAPP $\mathrm{wt}_{\mathrm{wt}}(\mathrm{n}=4$ for $\mathrm{sAPP} \alpha / \mathrm{sAPP} \beta ; \mathrm{n}=3$ for $\left.\mathrm{A} \beta_{40} / \mathrm{A} \beta_{42}\right)$. No human $\mathrm{sAPP} \alpha / \mathrm{sAPP} \beta$ or human $A \beta_{40} / A \beta_{42}$ was detected in control samples (ECLIA measurements were normalized to the protein content of each sample; Values are means \pm SEM; ${ }^{\star} \mathrm{P} \leq 0.05,{ }^{* *} \mathrm{P} \leq 0.01,{ }^{* *} \mathrm{P} \leq 0.001,{ }^{* * *} \mathrm{P} \leq 0.0001$, two-tailed unpaired $\mathrm{t}$-test with Welch's correction for $\mathbf{a} / \mathbf{b}$, twotailed paired t-test for $\mathbf{c} / \mathbf{d})$.

$\mathrm{A} \beta_{40}$, reaching $20 \mathrm{pg} / \mathrm{mg}$ protein while no human $\mathrm{A} \beta_{40} / \mathrm{A} \beta_{42}$ was detected in control samples (Fig. 1d). For comparison, we matched the recorded $A \beta$ levels from $h A P P_{w t}$ hippocampi to those observed in a well-established model of $\mathrm{AD}$, the $5 \times \mathrm{FAD}$ mice. In the latter, at the same age, $\mathrm{A} \beta_{40}$ levels reached around $600 \mathrm{pg} / \mathrm{mg}$ protein and $2500 \mathrm{pg} / \mathrm{mg}$ for $\mathrm{A} \beta_{42}$ on average (Suppl. Figure 1). We conclude that hAPP ${ }_{\mathrm{wt}}$ mice exhibit increased levels of soluble APP but low levels of $\mathrm{A} \beta_{40} / \mathrm{A} \beta_{42}$.

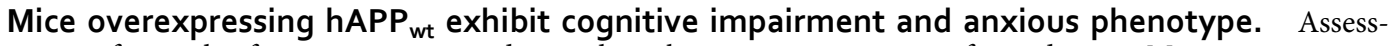
ments of spatial reference memory and spatial working memory were performed using Morris water maze (MWM) and modified Y-maze. Open field (OF), light-dark test (LDT), and elevated plus maze (EPM) tests were used to determine exploration behavior, locomotor activity and unconditioned anxiety response. In the modified Y-maze, animals could explore the maze for $10 \mathrm{~min}$ while one of its three arms was blocked. Thirty minutes later, mice were introduced to the Y-maze, with all three arms open and accessible. For the modified Y-maze, 6 and 12 month old hAPP ${ }_{\mathrm{wt}}$ and control littermates were used. At 6 months, control animals spent significantly more time $(\mathrm{P}=0.0362)$ in the newly accessible arm compared to the start or familiar arm of the modified Y-maze, while $\mathrm{hAPP}$ wt mice did not show any significant preference for any arm, pointing to impaired spatial working memory (Fig. 2a). At 12 months of age, control animals still showed a tendency, although not significant, to prefer the newly exposed arm compared to the start and familiar arm, while hAPP ${ }_{w t}$ mice did not show any 
a

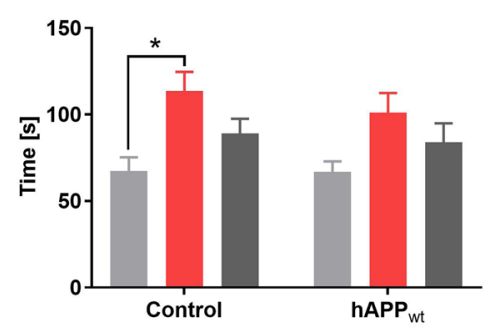

C

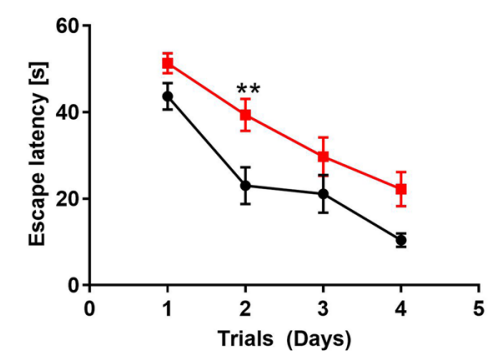

e

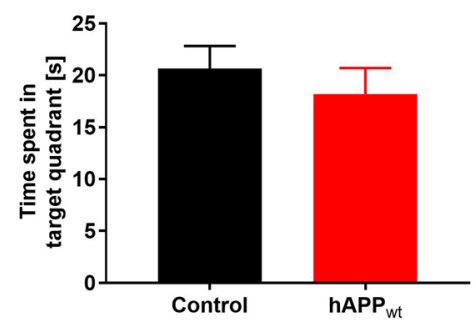

b

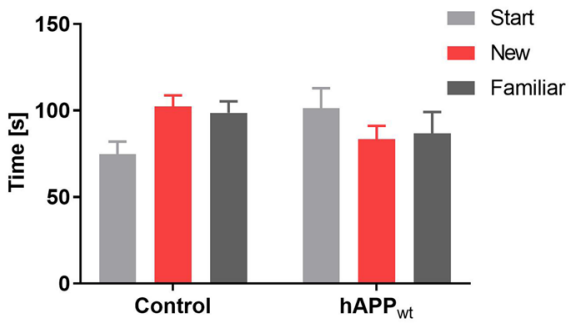

d

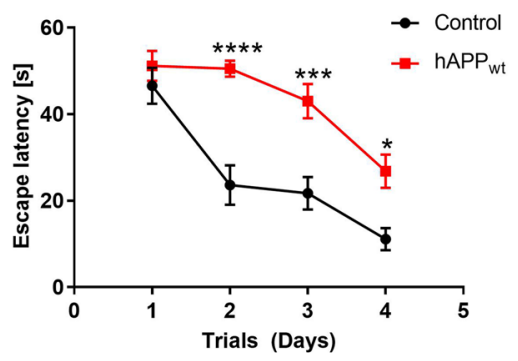

f

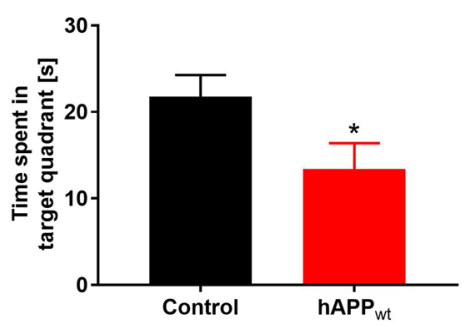

Figure 2. Performance of 6 month and 12 month old male hAPP ${ }_{w t}$ and control animals in behavioral tasks. (a) Recorded exploration time of the start, new and familiar arm of the modified Y-maze in 6 month old hAPP ${ }_{\mathrm{wt}}$ $(\mathrm{n}=16)$ vs. control $(\mathrm{n}=12)$ mice and $(\mathbf{b})$ in 12 month old hAPP $(\mathrm{wt}=8)$ and control $(\mathrm{n}=12)$ animals. (c) Recorded escape latency in the Morris water maze (MWM) compared between 6 month old hAPP $\mathrm{wt}_{(\mathrm{n}=16)}$ and control $(n=12)$ animals as well as $(\mathbf{d}) 12$ month old hAPP ${ }_{w t}(n=8)$ and control $(n=12)$ mice. (e) Recorded time spent in the target quadrant of the MWM during probe test (platform removed) of 6 month old hAPP $\mathrm{wt}_{\mathrm{w}}$ $(\mathrm{n}=16)$ and control $(\mathrm{n}=12)$ animals and $(\mathbf{f}) 12$ month old hAPP $\mathrm{wt}(\mathrm{n}=8)$ and control $(\mathrm{n}=12)$ mice. (Values are means \pm SEM; ${ }^{*} \mathrm{P} \leq 0.05,{ }^{* *} \mathrm{P} \leq 0.01,{ }^{* *} \mathrm{P} \leq 0.001,{ }^{* * *} \mathrm{P} \leq 0.0001$, two-way ANOVA with Sidak's post-hoc test for a-d, two-tailed unpaired t-test for $\mathbf{e} / \mathbf{f})$.

significant preference for any arm of the Y-maze (Fig. 2b). In the MWM, mice learn the location of a hidden platform using visual cues while the escape latency (time to reach the platform) is measured. On the first trial day, all hAPP ${ }_{w t}$ and control mice, reached the platform in about $50 \mathrm{~s}$ with no visible differences in swimming speed, suggesting the absence of any major locomotor defect. At 6 months of age, $\mathrm{hAPP}_{\mathrm{wt}}$ mice exhibited a significantly longer escape latency $(\mathrm{P}=0.009)$ on day 2 of the MWM test when the platform was invisible, but overall, still learned normally (Fig. 2c). The probe test that was performed on day 5 was normal, suggesting a normal spatial reference memory $(\mathrm{P}=0.4756$; Fig. $2 \mathrm{e})$. At 12 months of age however, the escape latency of $h A P \mathrm{P}_{\mathrm{wt}}$ mice was significantly longer on day $2(\mathrm{P} \leq 0.0001), 3(\mathrm{P}=0.0009)$, and $4(\mathrm{P}=0.0215)$ of the MWM (Fig. $2 \mathrm{~d})$. Additionally, the probe test showed a significant decrease $(\mathrm{P}=0.0480)$ in time spent in the target quadrant when the platform was completely removed from the MWM (Fig. 2f) suggesting an impairment in learning ability and an alteration in reference memory. Willingness to explore new environments, locomotor activity as well as anxiety was measured in the OF experiment and revealed that 6 month old $\mathrm{hAPP}_{\mathrm{wt}}$ mice entered the center of the OF significantly less frequently $(\mathrm{P}=0.0002$; Fig. $3 \mathrm{a})$ and spent significantly less time $(\mathrm{P}=0.0299)$ in the center of the OF compared to control littermates (Fig. 3b). These mice had however a similar locomotor activity $(9894 \pm 265 \mathrm{~cm} / 20$ min for control mice $n=12$ vs $9235 \pm 426 \mathrm{~cm} / 20$ min for hAPP ${ }_{w t}$ mice, $n=16$ ). Measurement of anxiety-like behavior was performed using the LDT and the EPM based on natural aversion of mice to brightly illuminated areas, and mild stressors such as novel environment. At 6 months of age, $\mathrm{hAPP}_{\mathrm{wt}}$ mice spent significantly $(\mathrm{P}=0.0261$ time in light area; $\mathrm{P}=0.0142$ distance moved) less time in the illuminated area compared to controls (Fig. $3 \mathrm{c} / \mathrm{d}$ ). In the EPM, 6 month old hAPP ${ }_{\text {wt }}$ mice tended to spend less time in the open arms but the difference did not reach statistical significance $(P=0.1196$; Fig. $3 e)$. Overall, $h_{A P P}$ mice exhibited impaired spatial reference learning 
a

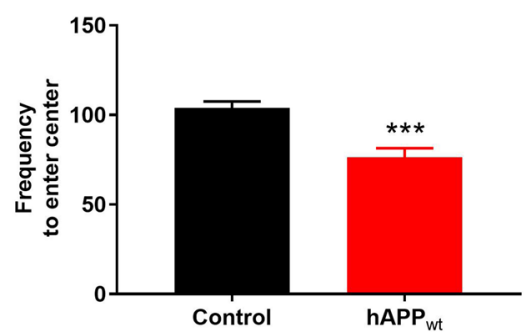

C

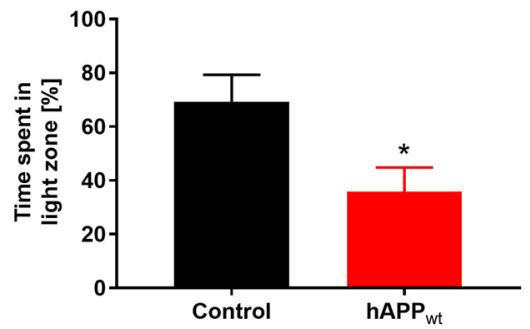

e

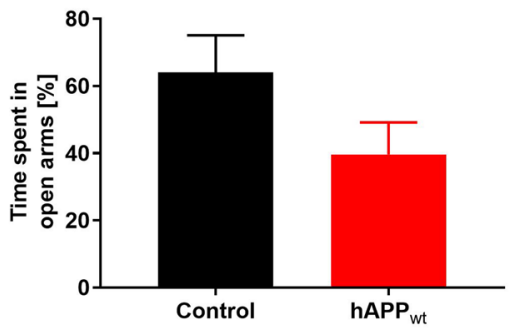

b

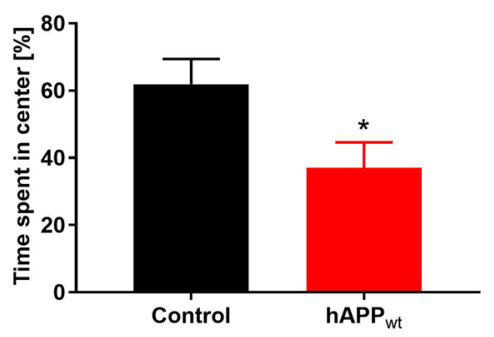

d

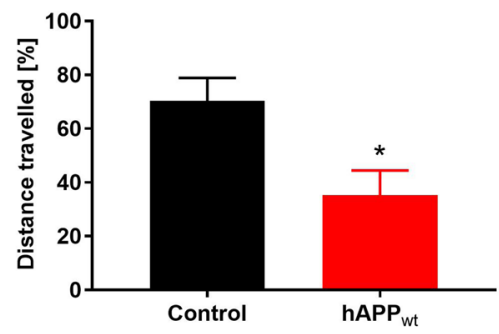

Figure 3. Assessment of anxiety-like behavior in 6 month old male hAPP ${ }_{\mathrm{wt}}$ mice and corresponding controls. (a) Frequency to enter the center of the open field (OF) was compared between $\mathrm{hAPP}_{\mathrm{wt}}(\mathrm{n}=16)$ and controls $(n=12)$. (b) Percentage of time spent in the center of the OF. (c) Percentage of time spent in the light zone of the light-dark test setup (LDT). (d) Distance travelled in the light zone of the LDT ( $n=10$ for hAPP ${ }_{w t}$ and $n=7$ for controls). (e) Percentage of time spent in the open arms of the elevated plus maze (EPM) ( $\mathrm{n}=10$ for hAPP and $\mathrm{n}=7$ for controls). (Values are means $\pm \mathrm{SEM}$; ${ }^{\star} \mathrm{P} \leq 0.05,{ }^{* *} \mathrm{P} \leq 0.001$, two-tailed unpaired $\mathrm{t}$-test for a and twotailed unpaired t-test with Welch's correction for $\mathbf{b}-\mathbf{e})$.

and memory that started at 6 months of age and fully manifested at 12 months, indicating impaired hippocampal function. Compared to controls, 6 month old hAPP ${ }_{\mathrm{wt}}$ animals also exhibited some reluctance to enter the center of the OF and avoided the illuminated area of the LDT suggesting increased anxious phenotype.

Overexpression of hAPP ${ }_{\text {wt }}$ leads to hippocampal neuronal death. The hippocampus plays a key role in memory consolidation and is one of the primary structures for functional and pathological alterations in $\mathrm{AD}$. We therefore analyzed possible changes in hippocampal morphology using $\mathrm{hAPP}_{\mathrm{wt}}$ mice and age-matched controls. Nissl stained sagittal brain sections $(5 \mu \mathrm{m})$ were obtained at 3, 6, 12 and 24 months of age. Compared to age-matched control littermates, the hippocampus of $\mathrm{hAPP}_{\mathrm{wt}}$ mice appeared to be thinner with missing or dead neurons specifically in the CA1 hippocampal area (Fig. 4a). The quantification of the number of viable neurons in the hippocampal CA1 region in $\mathrm{hAPP}_{\mathrm{wt}}$ and control littermates at 3,6, and 12 months of age is presented on Figs. $4 \mathrm{~b}-\mathrm{d}$. In all age groups, $\mathrm{hAPP}_{\mathrm{wt}}$ mice presented significantly less neurons ( 3 months $\mathrm{P}=0.0004 ; 6$ months $\mathrm{P} \leq 0.0001 ; 12$ months $\mathrm{P}=0.0009)$ in the CA1 area compared to controls suggesting neuronal loss. Furthermore, at 12 months of age, the Nissl staining revealed dark shrunken neurons in hPPP $_{w t}$ brain slices which typically indicate neuronal death (Fig. 4a) ${ }^{46}$. The presence of dead neurons was confirmed in 12 month old hAPP mice $_{\text {w }}$ by positive caspase- 3 staining, a cysteine-aspartic acid protease typically involved in cell death. Additionally, hippocampal sections were taken from 24 month old hAPP ${ }_{w t}$ animals at different lateral markers to investigate further neuronal loss (Fig. 4e). The Nissl stained hippocampal sections revealed the same dark shrunken neurons, that seemed to further advance into the hippocampus along the lateral axis indicating a spread of neuro- 
a

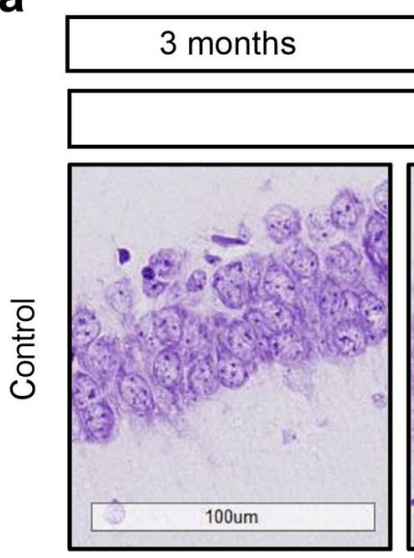

$\begin{array}{ll}6 \text { months } & 12 \text { months } \\ \text { Niss/ staining }\end{array}$

\begin{tabular}{|c|}
\hline 12 months \\
\hline Caspase-3 \\
\hline
\end{tabular}
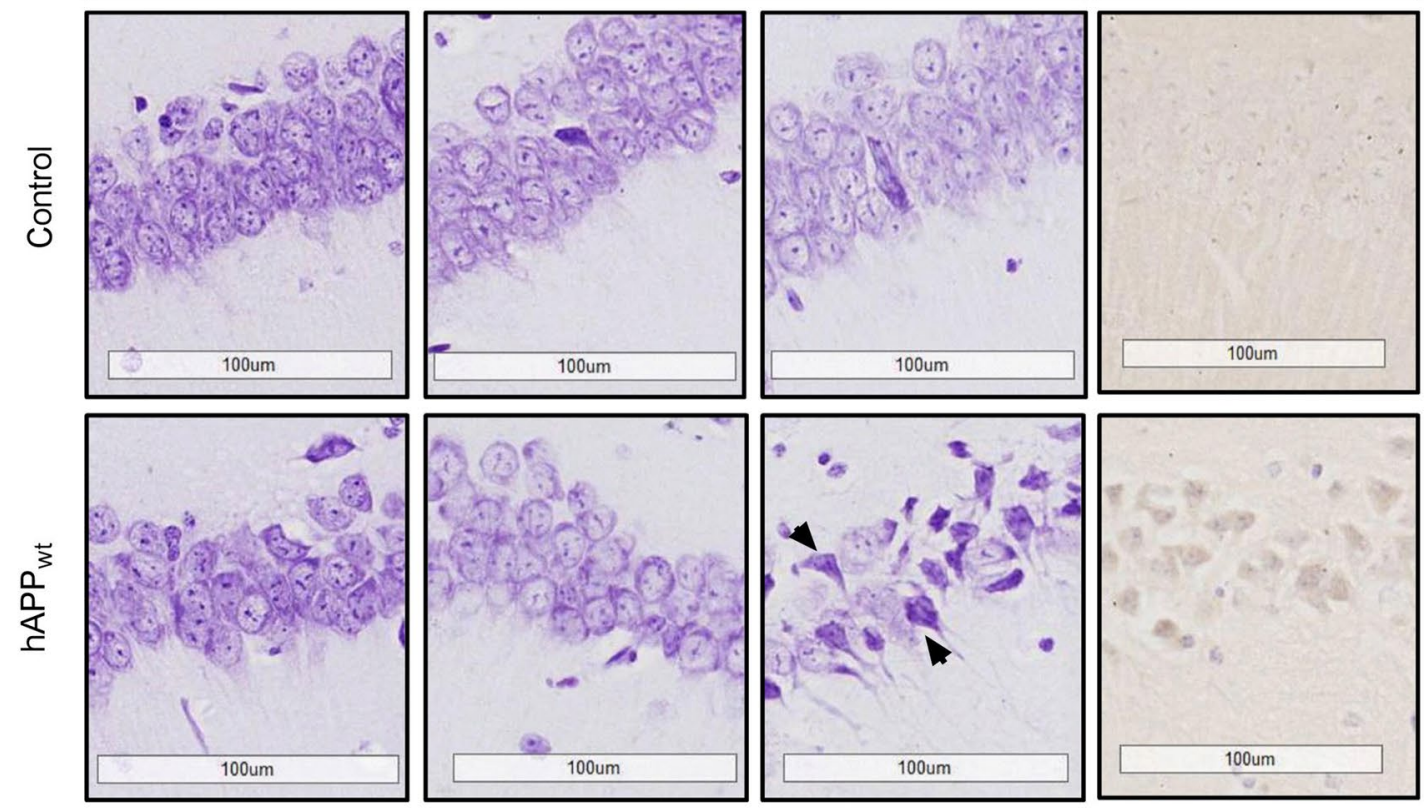

b

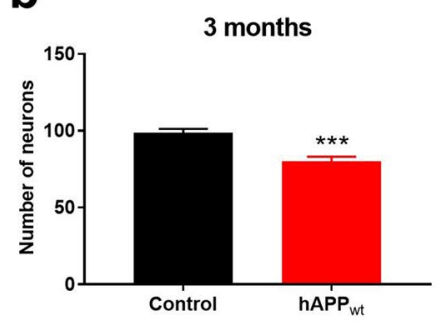

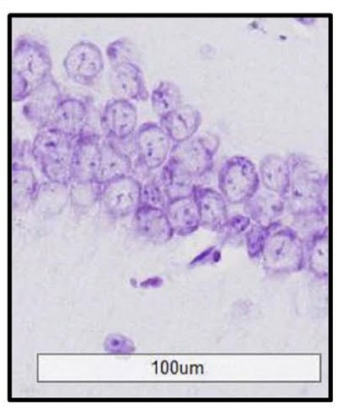

C

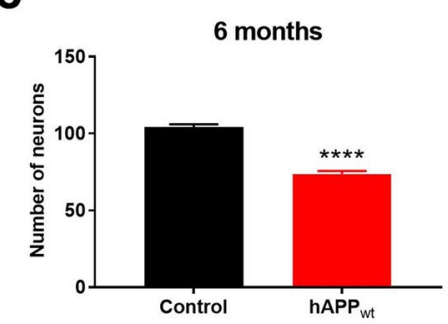

d

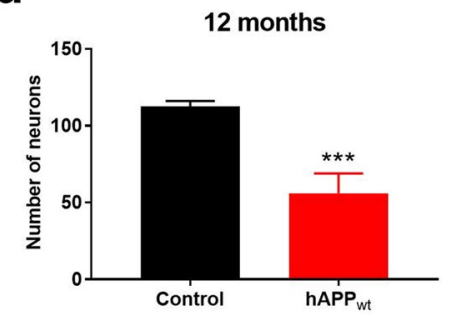

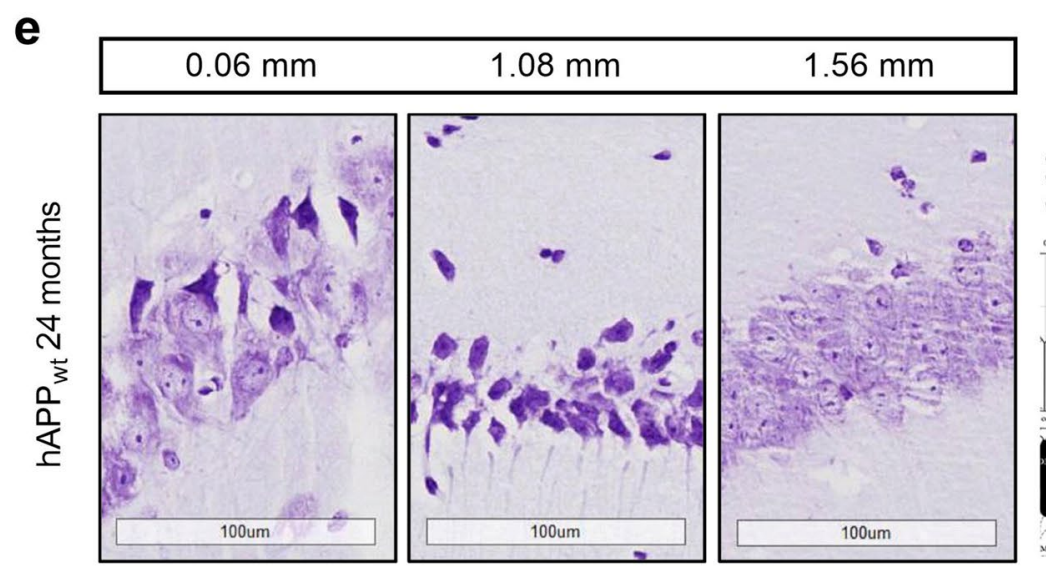

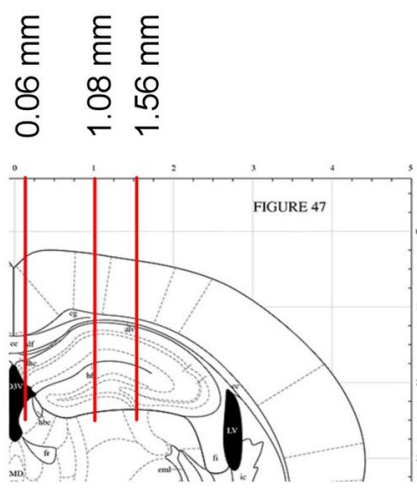

Figure 4. Morphological changes in the CA1 hippocampal region in male $\mathrm{hAPP}_{\mathrm{wt}}$ and age-matched control animals at 3-24 months of age. (a) Comparison of Nissl stained sagittal brain sections of the hippocampal CA1 area between $\mathrm{hAPP}_{\mathrm{wt}}$ and age-matched control littermates, starting at 3 months and progressing to 12 months of age. Arrows mark the presence of dark Nissl stained neurons in $\mathrm{hAPP}_{\mathrm{wt}}$ mice at 12 months of age, which is a sign of neuronal death. Neuronal degeneration and death were confirmed by caspase- 3 staining in 12 month old hAPP animals. (b-d) Quantification of surviving neurons in the CA1 area of 3, 6, and 12 month old hAPP ${ }_{\text {wt }}$ animals and age matched littermates. Neurons with round and palely stained nuclei were considered as viable, while shrunken and dark stained cells were considered as dead. Data are expressed as the number of surviving neurons per analyzed CA1 section $(300 \mu \mathrm{m} \times 300 \mu \mathrm{m})$ in each age group for $\mathrm{hAPP}_{\mathrm{wt}}(\mathrm{n}=8)$ and control $(\mathrm{n}=8)$ mice. (e) Nissl stained sagittal brain sections of the hippocampal CA1 area in 24 month old hAPP $\mathrm{wt}_{\mathrm{w}}$ mice reveal a lateral progression of neuronal degeneration, which is evident by the presence of dark Nissl stained neurons. Sections were taken later at $0.06 \mathrm{~mm}$, $1.08 \mathrm{~mm}$, and $1.56 \mathrm{~mm}$; values are means $\pm \mathrm{SEM} ;{ }^{* * *} \mathrm{P} \leq 0.001$, ${ }^{\star * * *} \mathrm{P} \leq 0.0001$, two-tailed unpaired $\mathrm{t}$-test). 
degeneration at 24 months of age. Taken together, the morphological changes in hAPP ${ }_{w t}$ mice could partially explain the cognitive impairment observed in $\mathrm{hAPP}_{\mathrm{wt}}$ mice.

Overexpression of $\mathrm{hAPP}_{\mathrm{wt}}$ leads to increased excitability and spontaneous spiking activity. Cognitive impairment and memory problems are commonly connected to impaired neuronal plasticity or aberrant excitability ${ }^{47,48}$. This was investigated in vivo and ex vivo, on brain slices. Intracranial EEG was monitored using electrodes implanted in CA1 hippocampal area (stratum pyramidale), dentate gyrus (DG; granule cell layer) and cortex of hAPP ${ }_{\text {wt }}$ and control animals at 6 and 12 months of age. EEG recordings revealed abnormal spikes in $\mathrm{hAPP}_{\mathrm{wt}}$ at 6 and 12 months but not in controls $(\mathrm{P}=0.0206$; Fig. $5 \mathrm{a} / \mathrm{b})$. This epileptiform activity largely decreased after treatment with baclofen, a pan-GABA $\mathrm{B}$ agonist (Fig. $5 \mathrm{c}$ ). Recorded spikes were unaccompanied by abnormal movements or convulsive seizures. To further characterize a possible impairment in neuronal excitability or plasticity, we performed extracellular field potential recordings on hippocampal slices of $\mathrm{hAPP}_{\mathrm{wt}}$ and control animals at 6 months of age. Schaffer collaterals (SCs) were stimulated electrically, and field excitatory postsynaptic potentials (fEPSPs) were recorded in the stratum radiatum of CA1 hippocampal region (Fig. 6). The relationship between the stimulus intensity and the fEPSP slope was similar in slices from both genotypes $(\mathrm{P}=0.7417$; Fig. $6 \mathrm{a})$. To study whether $\mathrm{hAPP}_{\mathrm{wt}}$ overexpression affects presynaptic properties of CA3CA1 synapses, we performed short-term facilitation induced by bursts of five stimuli at a frequency of $20 \mathrm{~Hz}$ (Fig. 6b). The observed short-term facilitation was significantly $(\mathrm{P}=0.0120)$ larger in brain slices from $\mathrm{hAPP}_{\mathrm{wt}}$ mice compared to controls, suggesting a decreased probability of neurotransmitter release at synapses. To induce long-term potentiation (LTP), we used a theta-burst stimulation (TBS) consisting of four trains of five pulses (at $100 \mathrm{~Hz}$ ) separated by an interburst interval of $200 \mathrm{~ms}$. In slices from control animals, TBS induced an increase of fEPSP response size to about $250 \%$ of the initial response (Fig. 6c). This potentiated response persisted up to the end of the experiment (at least one hour). In $\mathrm{hAPP}_{\mathrm{wt}}$ mice, LTP was significantly increased by a factor of about 2 in comparison to control mice $(\mathrm{P}=0.0362$; Fig. $6 \mathrm{c} / \mathrm{e})$. Treatment of $\mathrm{hAPP}_{\mathrm{wt}}$ brain slices with baclofen $(100 \mu \mathrm{M})$ diminished this abnormally elevated LTP observed in $\mathrm{hAPP}_{\mathrm{wt}}$ (Fig. $\left.6 \mathrm{~d} / \mathrm{f}\right)$. The response to TBS itself was in fact modified: in $\mathrm{hAPP}_{\mathrm{wt}}$ brain slices, the responses to the second $(\mathrm{P}=0.0006)$, third $(\mathrm{P}=0.0001)$ and fourth $(\mathrm{P}=0.0196)$ bursts of stimulation were globally increased in comparison to the responses to the first burst (Fig. 6g). This was not observed in control hippocampal slices.

Overexpression of $\mathrm{hAPP}_{\mathrm{wt}}$ does not alter the expression of inhibitory or excitatory receptors. We analyzed possible alterations caused by $\mathrm{hAPP}_{\mathrm{wt}}$ overexpression in proteins directly implicated in the process of inhibitory and excitatory signaling. GABA mediates its actions via fast acting ionotropic $\mathrm{GABA}_{\mathrm{A}} \mathrm{Rs}$ and slow metabotropic $\mathrm{GABA}_{\mathrm{B}}$ Rs. GABA $\mathrm{As}$ exhibit a pentameric channel structure consisting of five subunits arranged around a central pore. The subunits can be subdivided into seven structurally related subfamilies a 1-6, $\beta 1-4, \gamma 1-3, \varepsilon, \delta, \pi, \rho 1-3$ and $\theta^{49}$. Since the composition of $\mathrm{GABA}_{\mathrm{A}} \mathrm{Rs}$ is very variable, we focused on the most abundant subunits in the hippocampus. $\mathrm{GABA}_{\mathrm{A}} \mathrm{R} \alpha$-subunits are amply distributed in the hippocampus with $\alpha 1$, $\alpha 2, \alpha 3$ and $\alpha 5$ being the most abundant ${ }^{50}$. In contrast, slow metabotropic $G_{A B A} R_{B}$ s exert their regulatory effects on synaptic transmission by acting as autoreceptors and heteroreceptors by inhibiting neurotransmitter release at GABAergic and glutamatergic synapses, respectively. We investigated hippocampal protein levels of $\mathrm{GABA}_{\mathrm{A}} \mathrm{R}$ $\alpha 1, \alpha 2, \alpha 3$ and $\alpha 5$ as well as $G_{A B A} R$ using western blot. No significant changes were detected in respect to $\alpha 1$, $\alpha 3$ and $\alpha 5$ subunits apart from a slight increase in $\alpha 2(P=0.0191$; Fig. 7a). Separately, NMDARs are essential contributors to glutamatergic excitatory synaptic transmission, as well as to several forms of synaptic plasticity in the adult brain. Activation of NMDARs is also essential for the recruitment of AMPARs into silent synapses and for other types of $\mathrm{Ca}^{2+}$-dependent synaptic plasticity ${ }^{51,52}$. Using western blot, we analyzed the possible effect of APP overexpression on glutamatergic receptors, focusing on most abundant subunits of NMDAR (GluN2A and GluN2B) and AMPAR (GluA1 and GluA2) based on their expression in the CNS ${ }^{53}$. At 6 months of age hippocampal protein levels of AMPAR subunits GluA1 and GluA2 remained unchanged in hAPP $\mathrm{wt}_{\mathrm{wi}}$ me as well as controls (Fig. 7b). As for NMDAR subunits we only detected a small increase in GluN2B $(\mathrm{P}=0.0456)$ while GluN2A remained unchanged (Fig. 7b). Taken together, we did not detect any major changes in GABAergic/glutamatergic receptor subunits except a slight increase in $\mathrm{GABA}_{\mathrm{A}} \mathrm{R}$ a2 subunit and in NMDAR subunit GluN2B.

Overexpression of $\mathrm{hAPP}_{\mathrm{wt}}$ decreases GABA but not glutamate amount. Hippocampal contents of GABA and glutamate were measured using specific ELISA assays. Glutamate content in hAPP $\mathrm{wt}_{\mathrm{wip}}$ pocampi did not differ from control samples (Fig. 8a). In contrast, hippocampal GABA content was significantly $(\mathrm{P}=0.0237)$ decreased in mice overexpressing hAPP ${ }_{w t}($ Fig. $8 \mathrm{~b})$. These observations lead us to hypothesize that a decrease of GABA release might cause overexcitability and the increased response to TBS.

Overexpression of $\mathrm{hAPP}_{\mathrm{wt}}$ does not alter the amount of GAD65/67. The detected decrease in GABA could also arise from impaired GABA production. GABA is synthesized from glutamate by the enzyme glutamic acid decarboxylase (GAD65 and GAD67), in particular by GAD65, which is preferentially localized at GABAergic nerve terminals. We assessed hippocampal protein levels of GAD65/67 via western blot in 6 month old hAPP ${ }_{w t}$ and control mice (Fig. 8c). No significant changes were detected concerning the protein amount of GAD65/67, suggesting that GABA production capacity is not impaired in $\mathrm{hAPP}_{\mathrm{wt}}$ animals.

Overexpression of $\mathrm{hAPP}_{\mathrm{wt}}$ does not influence GABA shift in vivo. Regulation of cognitive processes depends on the fine tuning between excitatory and inhibitory neurotransmission. GABAergic neurotransmission is determined by the electrochemical gradient that depends on the intracellular chloride concentration $\left[\mathrm{Cl}^{-}\right]_{\mathrm{i}}$. The main players in regulating the $\left[\mathrm{Cl}^{-}\right]_{\mathrm{i}}$ in neurons are KCC2, the primary $\mathrm{Cl}^{-}$extruder and NKCC1, 
a

Control

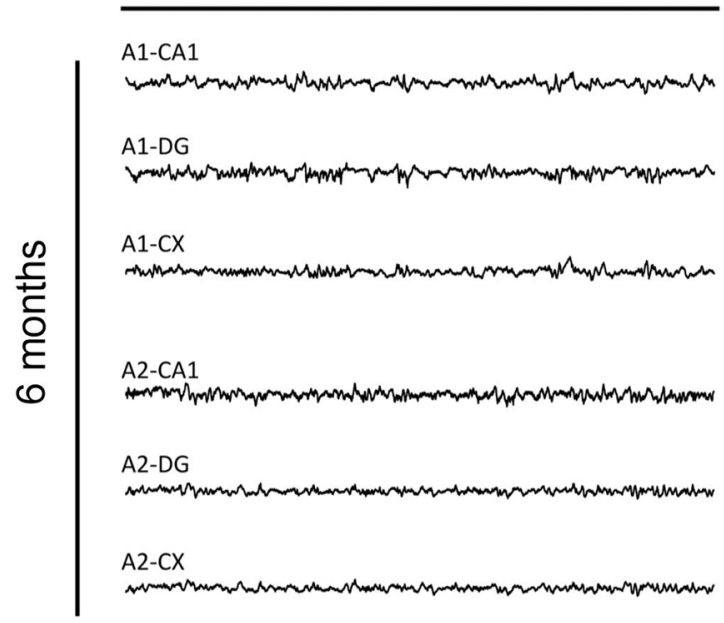

hAPP $_{\text {wt }}$

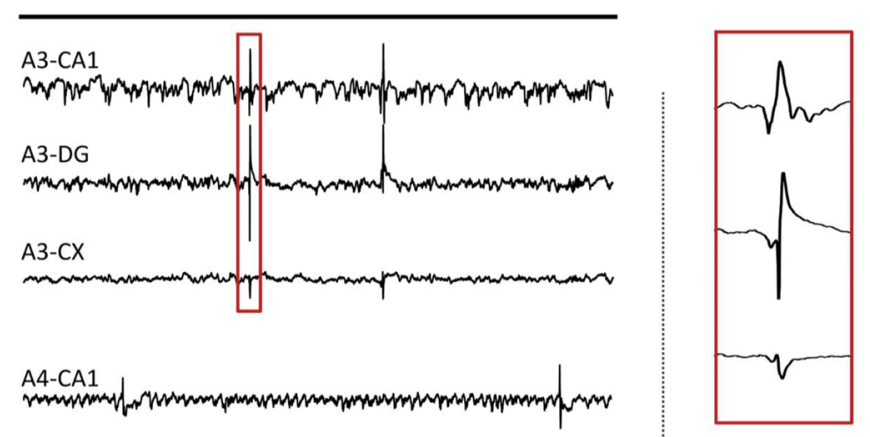

A4-DG

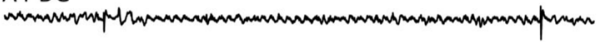

A4-CX
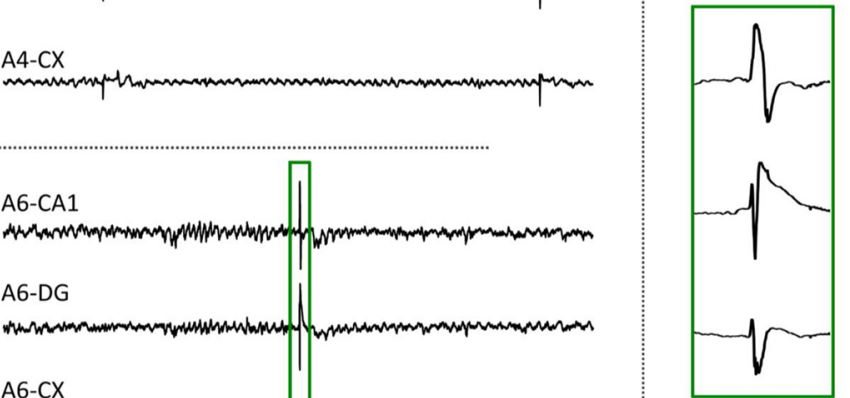

A6-CX

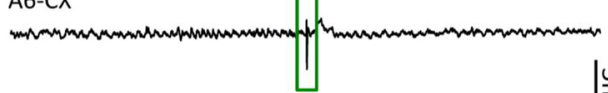

$\stackrel{3}{3}$

$150 \mathrm{~ms}$
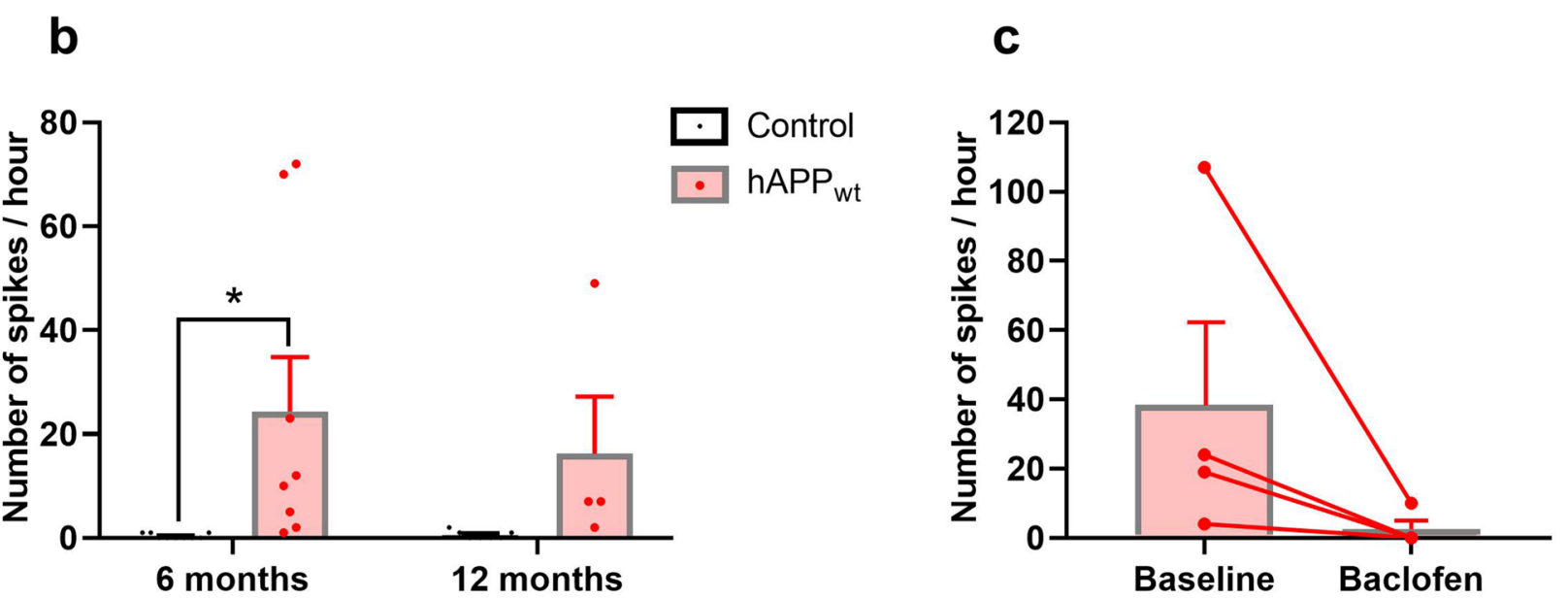

Figure 5. EEG recordings in 6 and 12 month old male hAPP ${ }_{w t}$ and control mice. (a) Electroencephalography (EEG) recordings of spontaneous spike activity documented in the hippocampus (CA1 area), dentate gyrus (DG), and cortex (CX) in 6 month old hAPP ${ }_{w t}$ (traces A3, A4) $(n=8)$ and controls (traces A1, A2) $(n=9)$ as well as 12 month old hAPP ${ }_{\text {wt }}$ (trace A6) $(n=4)$ and control (trace A5) $(n=7)$ mice. (b) Quantification of annotated number of spikes per hour in 6 and 12 month old $\mathrm{hAPP}_{\mathrm{wt}}$ and control mice with individual values for each animal represented by dots. (c) Abolishment of spiking activity after baclofen treatment in 6 month old hAPP ${ }_{w t}$ $(\mathrm{n}=4)$ mice. (Values are means $\pm S E M ;{ }^{\star} \mathrm{P} \leq 0.05$, two-way ANOVA with Sidak's post-hoc test).

the predominant $\mathrm{Cl}^{-}$importer. To assess the possible influence of $\mathrm{hAPP}$ wt overexpression on GABA efficacy, we measured hippocampal protein levels of KCC2 and NKCC1 in hAPP $\mathrm{wt}_{\mathrm{w}}$ mice and controls at 6 months of age (Fig. 8d). No significant changes in either KCC2 or NKCC1 were detected in the hippocampi of hAPP animals compared to controls, leading to the conclusion that mechanisms controlling the $\mathrm{Cl}^{-}$concentration are not impaired and therefore the ability of GABA to inhibit neuronal excitability should not be affected by the overexpression of $\mathrm{hAPP}_{\mathrm{wt}}$. 
a

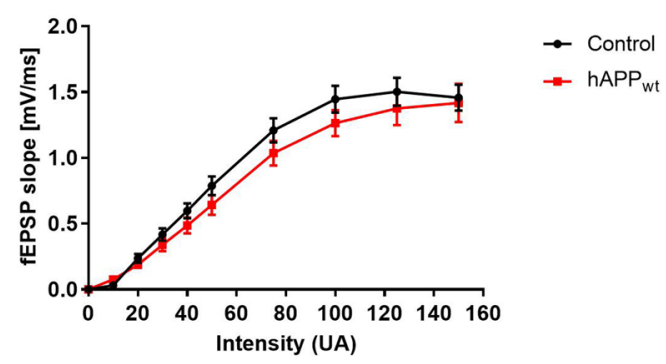

C

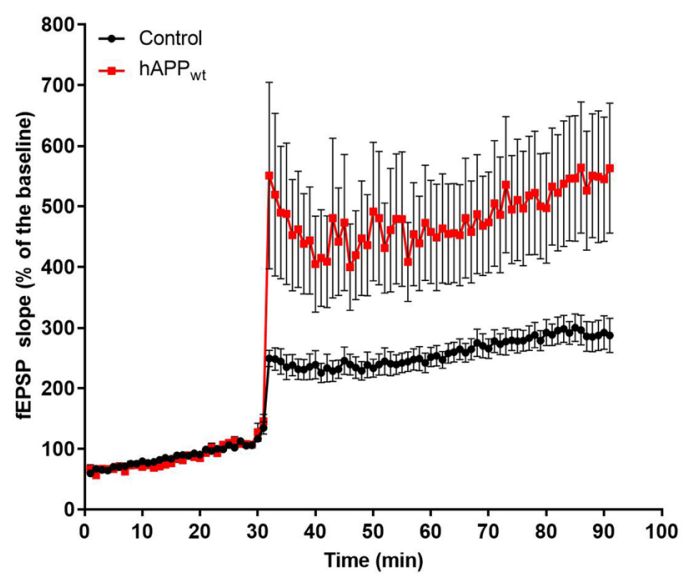

e

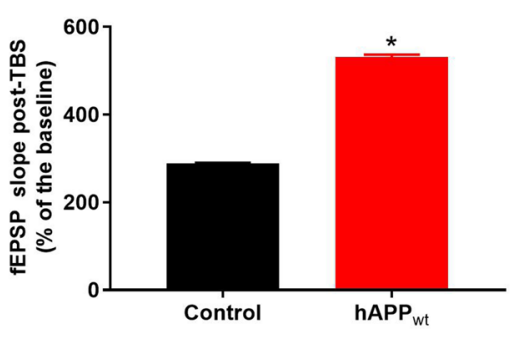

g

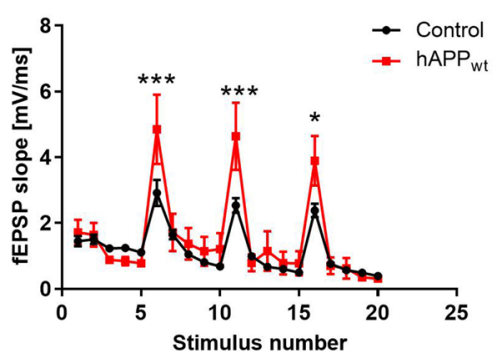

b

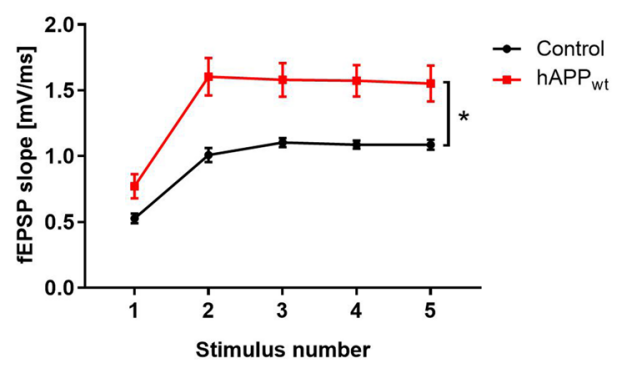

d

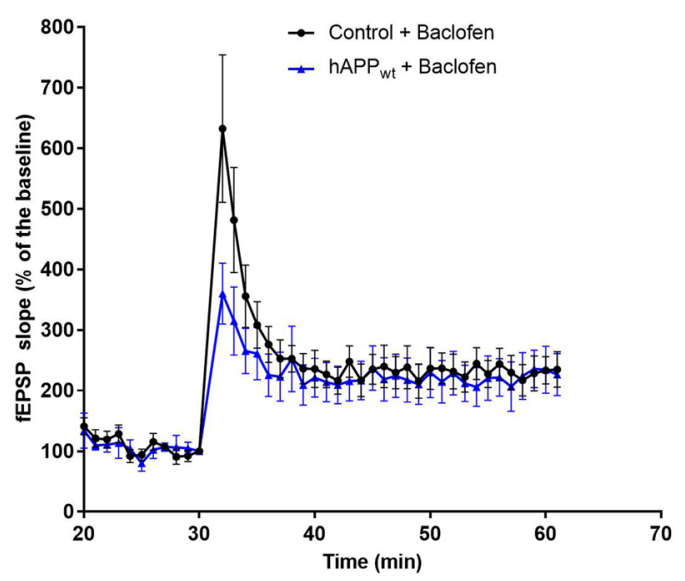

f

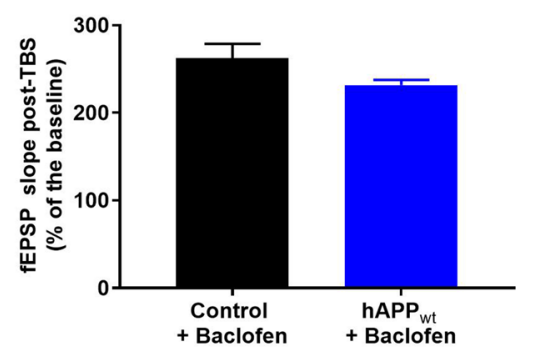

Figure 6. Increased LTP and short-term facilitation in 6 month old male hAPP ${ }_{w t}$ animals. (a) Current curves of hAPP $(\mathrm{wt}=51)$ and controls $(\mathrm{n}=48)$. (b) Short-term facilitation at $20 \mathrm{~Hz}$ stimulation frequency in $\mathrm{hAPP}_{\mathrm{wt}}$ $(\mathrm{n}=8)$ brain slices vs. controls $(\mathrm{n}=5)$. (c) LTP in hippocampal SC-CA1 pathway electrically stimulated by TBS in $\mathrm{hAPP}_{\mathrm{wt}}(\mathrm{n}=14)$ compared to controls $(\mathrm{n}=12)$. (d) Rescue of increased LTP response in hAPP mice $_{\mathrm{wt}}(\mathrm{n}=8)$ compared to controls $(\mathrm{n}=7)$ after perfusion with $100 \mu \mathrm{M}$ baclofen. (e) Quantification of LTP in hippocampal slices of hAPP ${ }_{w t}$ and controls after TBS introduction (corresponding to c) and (f) Quantification of LTP after baclofen perfusion (corresponding to d). (g) Increased fEPSP responses to TBS in $\mathrm{hAPP}_{\mathrm{wt}}(\mathrm{n}=5)$ animals compared to controls $(\mathrm{n}=4)$. (Values are means $\pm \mathrm{SEM} ;{ }^{*} \mathrm{P} \leq 0.05,{ }^{\star * *} \mathrm{P} \leq 0.001$, two-way ANOVA with Sidak's post-hoc test for $\mathbf{b}-\mathbf{g}$, two-tailed unpaired t-test for $\mathbf{a}$ ). 

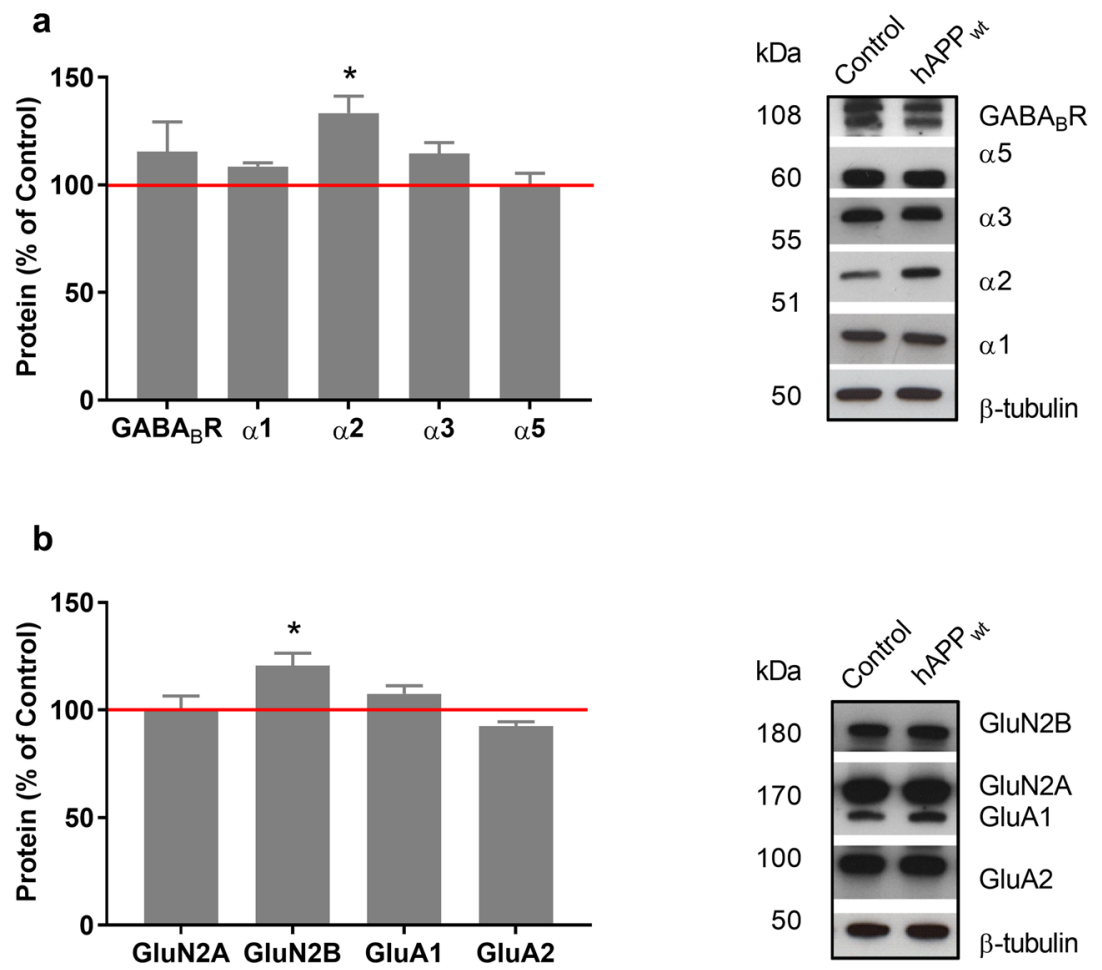

Figure 7. Protein levels of the main GABAergic and glutamatergic receptors in 6 month old male hAPP ${ }_{\mathrm{wt}}$ mice. (a) Quantification and representative western blots of GABAergic receptor protein levels, including $G_{A B A} R$ and $\mathrm{GABA}_{\mathrm{A}} \mathrm{R} \alpha 1, \alpha 2, \alpha 3$ and $\alpha 5$ subunits, measured in hippocampal tissue lysates of $\mathrm{hAPP}_{\mathrm{wt}}(\mathrm{n}=4)$ and control $(\mathrm{n}=4)$ animals. (b) Quantification and representative western blots of glutamatergic receptor subunits of NMDA receptor (GluN2A, GluN2B) and AMPA receptor (GluA1, GluA2) measured in hippocampal tissue lysates of hAPP ${ }_{w t}(n=4)$ and control $(n=4)$ animals. Protein amount was normalized to $\beta$-tubulin and expressed as percentage (Values are means $\pm \mathrm{SEM} ;{ }^{*} \mathrm{P} \leq 0.05$, two-tailed unpaired $t$-test with Welch's correction).

Rescue of increased excitability in hAPP $_{w t}$ mice with CGP36216. As mentioned before, we observed increased response to TBS in hippocampal slices of $\mathrm{hAPP}_{\mathrm{wt}}$ mice at 6 months of age. This effect has been related to the activation of presynaptic $\mathrm{GABA}_{\mathrm{B}}$ autoreceptors that inhibit GABA release and disinhibit the response. Increased response to TBS was completely rescued by application of $500 \mu \mathrm{M}$ CGP36216, a specific antagonist of $G_{A B A} R$ that acts only on presynaptic $G_{B A B} R^{54}$ (Fig. 9a). Similarly, the exaggerated short-term facilitation observed in $\mathrm{hAPP}_{\mathrm{wt}}$ hippocampal slices in response to five stimuli at $20 \mathrm{~Hz}$ returned to normal level after application of $500 \mu \mathrm{M}$ CGP36216 (Fig. 9b). Moreover, TBS-induced LTP that was shown to be exaggerated in 6 month old hAPP ${ }_{w t}$ mice, was largely reduced by the treatment with CGP36216 $(\mathrm{P}=0.0329$; Fig. 9c/d $)$.

\section{Discussion}

It is widely established that APP mutations, altering A $\beta$ production, can cause EOAD but the involvement of APP per se in its progression is not well understood ${ }^{55}$. However, synaptic function is affected at earliest stages of $\mathrm{AD}$, partially independent from $\mathrm{A} \beta$ plaque formation and accompanied by disruption of excitatory/inhibitory balance in animal models as well as patients ${ }^{6,7,48,56}$. We were interested to see if and how APP manages to modulate excitatory and/or inhibitory neurotransmission in the absence of APP mutations or A $\beta$ plaque formation. In this study we used a mouse model that overexpresses moderate levels of wild-type human APP (fourfold compared to wild-type animals) but generates very low levels of $A \beta_{40} / A \beta_{42}$ with no evident plaque formation ${ }^{18,44,57}$. The APP overexpression profile is comparable to a rare form of EOAD, in which the APP gene is duplicated (Dup-APP). In Dup-APP, chromosome 21 duplications can vary in size with the smallest known duplication containing an additional copy of $A P P$ without any other gene duplication ${ }^{58,59}$. Although the increase of APP is relatively small compared to our mouse model, individuals with Dup-APP still experience seizures ${ }^{60}$. In DS patients, APP overexpression occurs due to triplication of chromosome 21. Interestingly, both neurodegenerative diseases share a common profile and are both associated with seizures and epilepsy ${ }^{61}$. In our study, morphological examination of $\mathrm{hAPP}_{\mathrm{wt}}$ and control mice brains, revealed a decrease of pyramidal cells in the CA1 hippocampal region with distinct cell death evidenced by caspase-positive cells in $\mathrm{hAPP}_{\mathrm{wt}}$ mice at 12 months of age. Neuronal loss in this particular model has been reported before ${ }^{57}$, but it is still not clear if GABAergic and glutamatergic neurons are affected equally. Since we did not observe any major changes in the expression of GABAergic/glutamatergic receptors or in GABA production enzymes, it is highly likely that both neuronal populations are affected. Impairment in adult neurogenesis due to overexpression of $\mathrm{hAPP}_{\mathrm{wt}}$ could also be partially responsible 
a

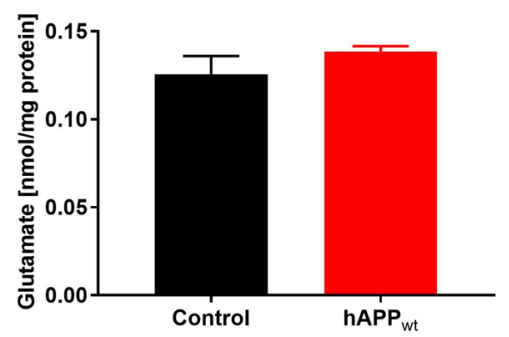

C

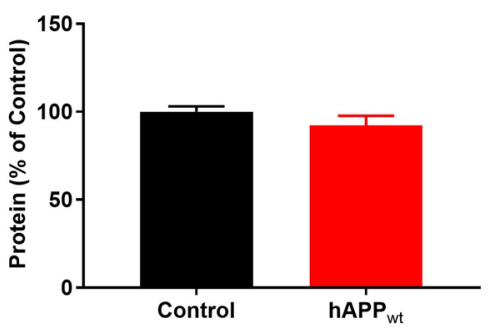

d b

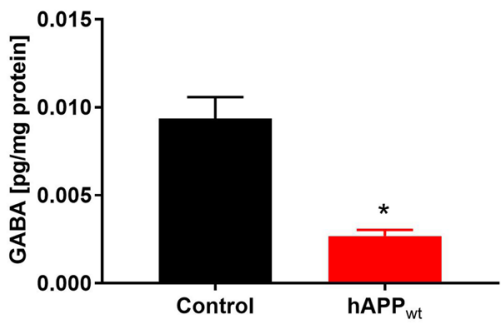

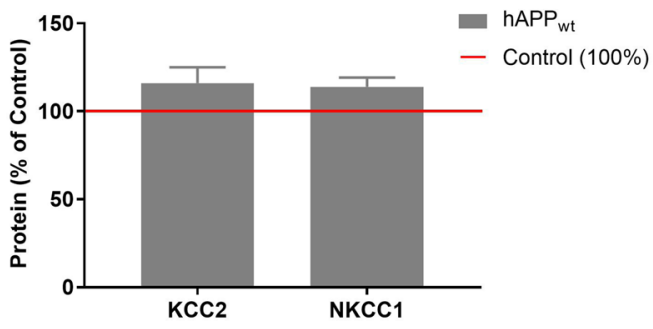

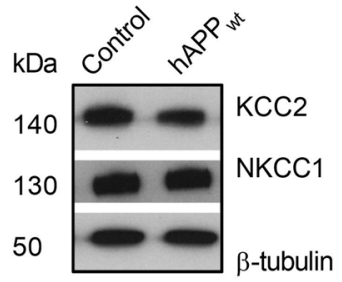

Figure 8. Quantitative determination of GABA content, production, and efficacy in 6 month old male hAPP mice. (a) ELISA measurements of free glutamate content in hippocampal tissue lysates of $\mathrm{hAPP}_{\mathrm{wt}}(\mathrm{n}=4)$ and control $(\mathrm{n}=4)$ animals. (b) GABA ELISA measurements in hippocampal tissue lysates of $\mathrm{hAPP}_{\mathrm{wt}}(\mathrm{n}=4)$ and control $(\mathrm{n}=4)$ mice. (c) Quantification and representative western blots of two glutamic acid decarboxylase isoforms (GAD65 and GAD67) using a combined antibody on hippocampal tissue lysates of $h A P P_{w t}(n=3)$ and controls $(\mathrm{n}=3)$. (d) Protein levels of KCC2 and NKCC1 were obtained from hippocampal tissue lysates hAPP $\mathrm{wt}_{\mathrm{wt}}$ $(n=4)$ and control $(n=4)$ mice. Quantification and representative western blots are displayed. For all western blots, the protein amount was normalized to $\beta$-tubulin and expressed as percentage. ELISA measurements were normalized to protein content of each sample (Values are means $\pm \mathrm{SEM},{ }^{\star} \mathrm{P} \leq 0.05$, two-tailed unpaired $\mathrm{t}$-test with Welch's correction).

for the neuronal decline in the hippocampi of 3, 6, and 12 month old hAPP ${ }_{\mathrm{wt}}$ animals ${ }^{62}$. The decrease in newborn neurons was more acute in $\mathrm{hAPP}_{\mathrm{wt}}$ (the line $\mathrm{I} 5$ we used in the present paper) compared to a similar model of APP overexpression, the hAPP-J20 mouse line, that overexpresses APP with a Swedish-Indiana mutation and exhibits high $A \beta$ levels with amyloid plaque formation, therefore suggesting that hAPP itself more than $A \beta$ is an important factor inhibiting adult neurogenesis ${ }^{44,62}$. Additionally, moderate levels of $\mathrm{hAPP}_{\mathrm{wt}}$ were sufficient to induce electrophysiological abnormalities. EEG recordings indeed revealed abnormal synchronous spiking activity in the DG, CA1 area, and cortex of 6 and 12 month old hAPP ${ }_{\text {wt }}$ animals, while no such activity was observed in controls. These changes occurred at very low $A \beta$ levels and in the absence of amyloid plaques, suggesting the importance of hAPP and its non-amyloid metabolites. However, it has been reported that even picomolar concentrations of $A \beta$ can lead to increased excitability ${ }^{63,64}$. In a recent study, Johnson et al. showed that familial AD-linked APP mutations could cause non-convulsive epileptiform activity in the absence of APP overexpression but that overexpression of $\mathrm{hAPP}_{\mathrm{wt}}$ could cause similar dysfunctions in the absence of such mutations ${ }^{18}$. This reproduced the situation observed in patients presenting APP mutations (some forms of AD) or APP overexpression (e.g. gene duplication) and showed that $\mathrm{hAPP}_{\mathrm{wt}}$ itself and its metabolites contribute to EEG abnormalities and to the hyperexcitability state, as it was suggested previously ${ }^{17,18}$. APP cleavage by ADAM10 or BACE1 liberates soluble APP fragments such as sAPP $\alpha /$ sAPP $\beta$ as well as membrane bound carboxyl-terminal fragments $\mathrm{CTF} \alpha / \mathrm{CTF} \beta$ that serve as precursors to APP intracellular domain fragments (AICDs). Simón and colleagues detected increased levels of CTFs in $\mathrm{hAPP}_{\mathrm{wt}}$ mice as well and further established that significantly more CTF $\alpha$ is produced compared to CTF $\beta$, leading to the conclusion that APP is largely processed in the non-amyloidogenic 

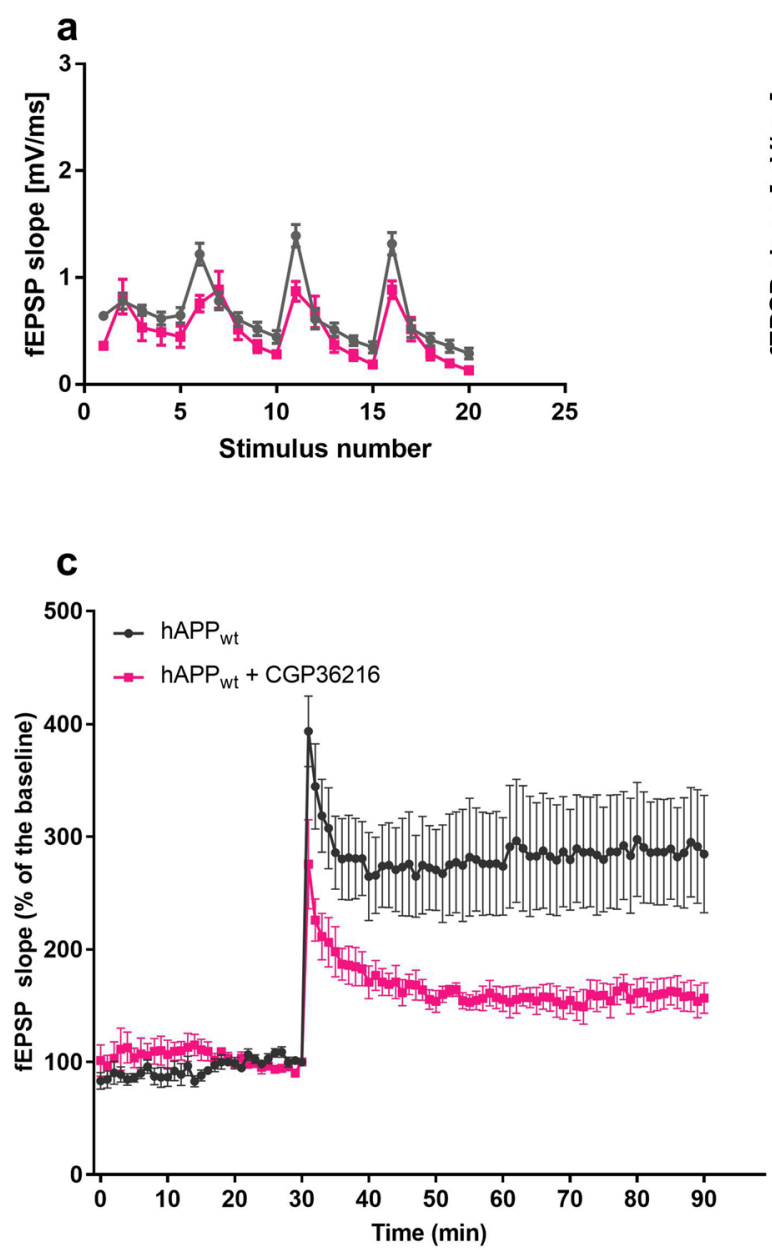
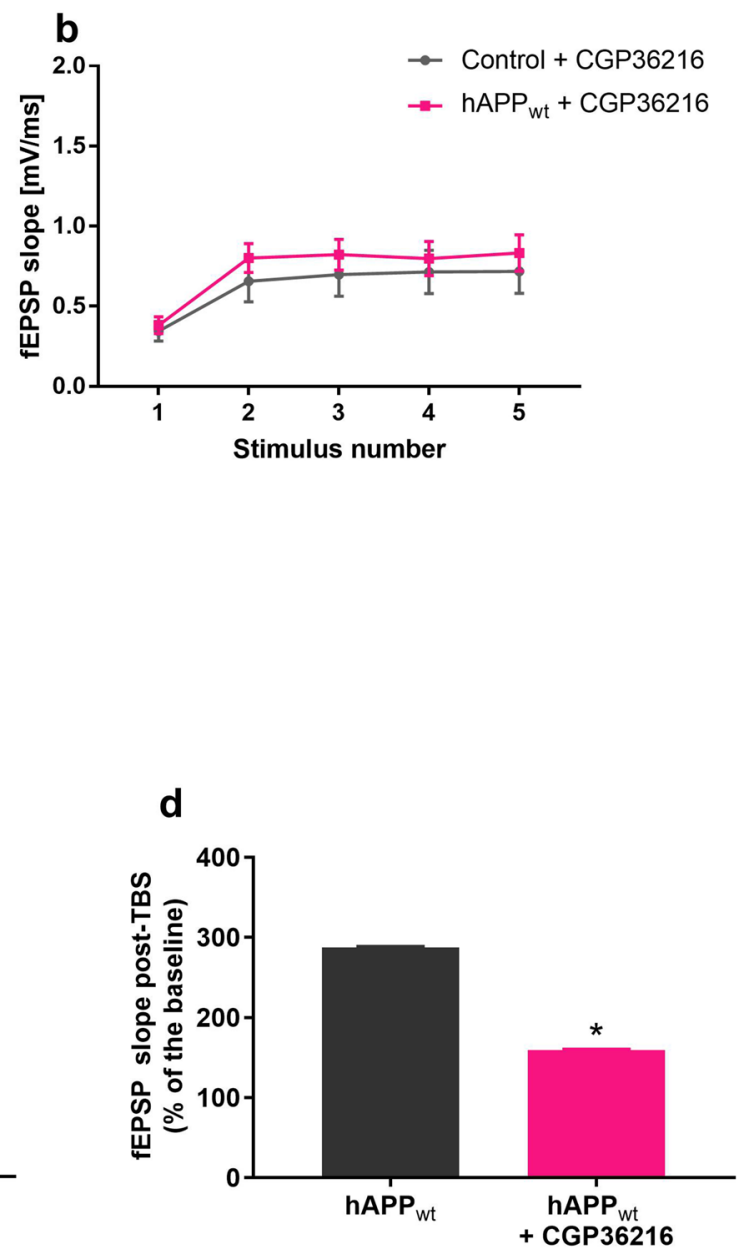

Figure 9. Rescue of increased excitability in 6 month old hAPP ${ }_{w t}$ mice with CGP36216. (a) Rescue of elevated TBS response in hippocampal slices of $\mathrm{hAPP}_{w t}(n=5)$ vs. control $(n=5)$ and $(\mathbf{b})$ Recovery of increased response to short-term facilitation during perfusion with $500 \mu \mathrm{M}$ CGP36216 in hippocampal slices of $\mathrm{hAPP}_{\mathrm{wt}}(\mathrm{n}=6)$ and control $(n=6)$ animals. (c) Rescue of increased LTP recorded in $\mathrm{hAPP}_{\mathrm{wt}}$ mice $(\mathrm{n}=5)$ and $\mathrm{hAPP}_{\mathrm{wt}}$ mice $(\mathrm{n}=5)$ perfused with $500 \mu \mathrm{M}$ CGP36216. (d) Quantification of LTP with CGP36216 perfusion (corresponding to c). (Values are means $\pm \mathrm{SEM} ;{ }^{\star} \mathrm{P} \leq 0.05$, two-way ANOVA with Sidak's post hoc test).

pathway ${ }^{57}$. Besides increased CTFs, hAPP ${ }_{w t}$ exhibited elevated levels of APP intracellular domains (AICDs) ${ }^{57}$ which can be a product of both APP processing pathways and can cause alterations in hippocampal network oscillations and cognitive impairment ${ }^{65}$. Furthermore, hAPP $_{w t}$ mice show increased levels of phosphorylated $\mathrm{tau}^{57}$ which could be the result of APP overexpression or increased levels of APP metabolites that cannot be excluded as a possible cause for neurodegeneration or increased excitability observed in hAPP $\mathrm{wt}_{\mathrm{wnimals}}{ }^{66}$. APP is present at synaptic sites which makes it a highly probable binding partner for receptors and gives it the capability to affect neurotransmission. Anatomical studies have shown that $\mathrm{GABA}_{\mathrm{A}} \mathrm{R} \alpha$-subunits are highly expressed in the hippocampus with large population of $\mathrm{GABA}_{\mathrm{A}} \mathrm{Rs}$ containing $\alpha 1, \alpha 2, \alpha 3$, and $\alpha 5^{67,68}$. In $\mathrm{AD}$ patients, GABAergic signaling is altered with a decreased profile of various $\mathrm{GABA}_{\mathrm{A}} \mathrm{R}$ subunits ${ }^{69}$. In mice lacking APP, $\mathrm{GABA}_{\mathrm{A}} \mathrm{R}$ al is significantly decreased as well ${ }^{38,70}$. However, in $\mathrm{hAPP} \mathrm{wt}_{\mathrm{t}}$ mice, al protein levels remained unchanged at 6 months. This was also the case for $\alpha 3$ and $\alpha 5$ subunits, which are primarily expressed in the hippocampus and are involved in hippocampus-dependent learning and memory ${ }^{71,72}$. We observed an increase of a2 subunit, which could explain the increased unconditioned anxiety detected in $\mathrm{hAPP}_{\mathrm{wt}}$ mice, a process mediated by $\alpha 2$ containing $\mathrm{GABA}_{\mathrm{A}} \mathrm{Rs}^{68,73}$. $\mathrm{GABA}_{\mathrm{A}} \mathrm{R}$-mediated responses are also determined by the intracellular $\mathrm{Cl}^{-}$concentration $\left(\left[\mathrm{Cl}^{-}\right]_{\mathrm{i}}\right)$. Cation-chloride transporters such as KCC2 and NKCC1 are involved in $\left[\mathrm{Cl}^{-}\right]_{\mathrm{i}}$ regulation and imbalance in their expression or function can disrupt GABAergic inhibition ${ }^{34,35}$. We previously showed that overexpression of APP in vitro decreases KCC2 expression leading to decreased inhibitory function of $\mathrm{GABA}^{37}$. In contrast, Ts65Dn mouse model of DS exhibits increased NKCC1 levels leading to the same outcome ${ }^{15}$. There is also an indication that APP actually interacts with $\mathrm{KCC} 2$, stabilizing the transporter at the cell surface and ensuring its function ${ }^{38}$. Surprisingly, here we show that protein levels of KCC2 and NKCC1 remained

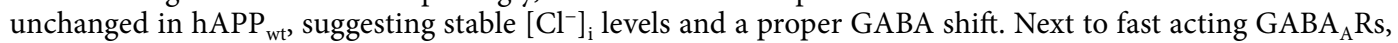
$\mathrm{GABA}_{\mathrm{B}} \mathrm{Rs}$ mediate slow and prolonged inhibitory synaptic signals. Here we demonstrate that their expression was not altered in $\mathrm{hAPP}_{\mathrm{wt}}$ mice at 6 months of age. The molecular diversity in the $\mathrm{GABA}_{\mathrm{B}}$ Rs arises from two different subunit isoforms $G A B A_{B} R_{1 a}$ and $G A B A_{B} R_{1 b}$. These subunits differ mainly in the presence of a sushi 
domain in $\mathrm{GABA}_{B} \mathrm{R}_{1 \mathrm{a}}$, and together with $\mathrm{GABA}_{B} \mathrm{R}_{2}$ form a functional receptor ${ }^{74}$. GABA can act on presynaptic $\mathrm{GABA}_{\mathrm{B}}$ Rs on GABAergic terminals (autoreceptors) inhibiting further release of GABA through feed-forward inhibition. $\mathrm{GABA}_{\mathrm{B}} \mathrm{Rs}$ are also located at glutamatergic terminals where they act as heteroreceptors since GABA from active interneurons can spill over to pre- and postsynaptic $\mathrm{GABA}_{\mathrm{B}} \mathrm{Rs}$ on excitatory synapses ${ }^{75}$. In addition, $\mathrm{GABA}_{\mathrm{B}} \mathrm{Rs}$ can reduce $\mathrm{Ca}^{2+}$ permeability of NMDARs in dendritic spines and enhance the $\mathrm{Mg}^{2+}$ block of the receptor $^{76}$. Vice versa, activation of NMDARs by glutamate can start a cascade involving CaMKII and 5 ' adenosine monophosphate-activated protein kinase (AMPK) which phosphorylates $\mathrm{GABA}_{\mathrm{B}}$ Rs triggering endocytosis of the receptor ${ }^{77,78}$. Our results demonstrate that at 6 months of age, $\mathrm{hAPP}_{\mathrm{wt}}$ mice present a slight increase in the NMDAR subunit GluN2B, the expression and the distribution of which might interfere with LTP and memory formation ${ }^{79}$. However, the change observed was very modest and Simón and colleagues reported a more important decrease in the expression of glutamatergic receptors and changes in synapse-associated proteins in $h A P P_{w t}$ mice starting at 8 months, indicating that major NMDAR/AMPAR changes occur later and were probably not detectable at 6 months of age ${ }^{57}$. APP is highly expressed in GABAergic interneurons in the mouse hippocampus ${ }^{40}$ with APP forming a complex with $G_{A B A} R$ s, specifically $G A B A_{B} R_{1 a}$ subunit simultaneously regulating bioavailability and localization of $A P P$ and $G A B A_{B} R^{42}$. APP deficits can therefore have an impact on presynaptic inhibition due to reduced $G_{A B A} R_{1 a}$ transport. Furthermore, the formation of APP-GABA $R_{1 a}$ complex protects APP from cleavage by $B A C E 1$ and therefore reduces $A \beta$ production ${ }^{42}$. We detected a significant production of human sAPP $\alpha$ and to a lesser extent sAPP $\beta$ in hippocampal samples obtained from hAPP ${ }_{w t}$ animals. Moreover, sAPP $\alpha$ and sAPP $\beta$ contain an extension domain that consequently binds to the sushi domain of $G_{A B A_{B}} R_{1 a}$, a process that decreases the probability of neurotransmitter release ${ }^{43}$. On brain slices of hAPP ${ }_{w t}$ mice, we observed an increased short-term facilitation at the SC-CA1 synapses as well as an increased LTP induced by TBS. The fact that LTP is increased whereas spatial reference memory is impaired may appear surprising as LTP is classically considered as the cellular mechanism that undergoes experience-dependent changes in synaptic connections and information storage. However, such apparent dissociation between LTP and memory has been observed in mice expressing mutant postsynaptic density protein- $95^{80}$, in mice with forebrain specific ablation of Stim genes ${ }^{81}$ or after ablation of Gia $1^{82}$. To explain this effect, Pineda and colleagues hypothesized that amplified responsiveness of CA1 postsynaptic neurons to stimuli would saturate LTP and diminish synapse-specific plasticity required for new memory formation ${ }^{82}$. Recently, a study performed by Rice and colleagues demonstrated that sAPP $\alpha$ per se triggers short-term facilitation in hippocampal neurons ${ }^{43}$. Besides, sAPPa enhances LTP and is sufficient to rescue the decrease of LTP observed in APP KO mice ${ }^{83,84}$. The response to the TBS itself is consistent with a decreased GABA release in $h A P P_{w t}$ mice. Binding of sAPP $\alpha$ to presynaptic $G_{A B A} R_{1 a}$ would diminish GABA release and therefore increase the disinhibitory process observed between the first and the second burst of stimuli during the TBS ${ }^{85}$. The effect of SAPPa (or other APP metabolites) in enhancing LTP and excitability by acting on presynaptic $G_{A B A} R_{1 a}$ shown in the present study, does not preclude the effect sAPPa recently shown on pre- and/or postsynaptic a7-nAChR receptors ${ }^{86}$. While levels of glutamate remained unchanged at 6 months of age, GABA significantly decreased in $\mathrm{hAPP}_{\mathrm{wt}}$ mice compared to controls. Simultaneously, we did not observe any changes in GAD65/67 proteins that are responsible for GABA production. In contrast, an increase in GAD65 expression accompanied with elevated GABA levels have been reported in APP KO mice ${ }^{70}$ which is a possible compensatory mechanism accounting for decreased number of GABAergic neurons or alterations in spine density $^{87,88}$. CGPs are common compounds to regulate GABAergic receptors and have been used in Ts65Dn mice to improve LTP (CGP55845) ${ }^{89}$ or to attenuate the sAPPa-mediated reduction of fEPSP frequency in hippocampal neurons (CGP55845, CGP54626) ${ }^{43}$ antagonizing both pre- and postsynaptic GABA ${ }_{B}$ Rs. Here, we were able to utilize CGP36216, a specific $G_{A B A} R$ antagonist that only acts on presynaptic $G_{B B A} R_{B}{ }^{54}$ and to show that the observed increased excitability in $\mathrm{hAPP}_{\mathrm{wt}}$ animals was due to decrease in GABA content not glutamate. Administration of CGP36216 was successful in reducing increased excitability in hAPP ${ }_{\mathrm{wt}}$ mice during TBS and shortterm facilitation. Taken together, disturbances in network synchronization and oscillatory activity are prevalent in $\mathrm{AD}$ and $\mathrm{DS}$ patients before the onset of neurodegenerative pathology. Our study emphasizes the role of APP in GABAergic transmission in the absence of amyloid plaques and APP mutations. Therefore, enhancing GABAergic inhibition could be a compelling way to prevent early seizures and neuronal overexcitation in affected individuals as well as reinforce the balance between excitatory and inhibitory signaling.

\section{Materials and methods}

Animals. Mice overexpressing human wild-type APP under the platelet-derived growth factor (PDGF-hAP$\mathrm{P}_{\mathrm{wt}}$ ) have been obtained from Charles River France (stock \#004,662) and have been described in detail in the past (I5 line) ${ }^{44,57}$. All transgenic mice were heterozygous with respect to the transgene while non-transgenic littermates served as controls. The present study was conducted using male mice at 3 to 24 months of age. Animals were housed and handled according to the Belgian Council on Animal Care guidelines based on protocols approved by the Animal Ethics Committee of the Universite catholique de Louvain. All experiments were carried out in compliance with the ARRIVE guidelines.

Behavior. Modified Y-maze. As previously described ${ }^{90}$ the modified Y-maze is commonly used for assessment of spatial and working memory and consists of three identical opaque open arms. In the modified Y-maze test, mice underwent two consecutive trials. During the first trial only two arms were accessible. Mice were placed in the Y-maze and were allowed to explore the two accessible arms during $10 \mathrm{~min}$. In the second trial, after 30 min inter-trial interval, the third arm was opened and the mice placed back into the Y-maze and had access to all the arms during a time period of $5 \mathrm{~min}$. Mice were video tracked (Ethovision 6.1, Noldus; Wageningen, Netherlands) and the time spent in the novel arm versus familiar arms, the latency to enter the novel arm as well as the number of entries into the novel versus familiar arms were recorded. 
Open field. During the open field test (OF), in two consecutive days animals were allowed to roam free in the OF without any influence of the examiner. Mice were placed in a square area $(60 \times 60 \mathrm{~cm})$ and video recorded (Ethovision 6.1) for $20 \mathrm{~min}$. During experimental procedure time spent in the center and the frequency to enter the center of the OF were measured.

Light-dark test. Unconditioned anxiety was assessed using the light-dark test (LDT) consisting of a cage divided into two sections of equal size by a partition with a door, with one side illuminated while the other side remained dark. Animals were transferred into the testing room $30 \mathrm{~min}$ before trial. At the beginning of the trial, mice were placed into the dark chamber (considered to be a safe area) and were allowed to move freely between the chambers for $10 \mathrm{~min}$. Time spent as well as distance travelled in the illuminated chamber was recorded by a video tracking system (Ethovision 6.1).

Elevated plus maze. The elevated plus maze test (EPM) was used to assess anxiety in mice and has been described before ${ }^{91}$. Briefly, mice were placed in an elevated plus maze consisting of two opposing open arms (exposed area) and two opposing closed arms (safe area). The time spent in each arm was recorded by a video tracking system (Ethovision 6.1) for a period of $5 \mathrm{~min}$.

Morris water maze. The Morris water maze (MWM) test was used to assess spatial learning and memory ${ }^{92}$. The maze consisted of a round pool with a diameter of $113 \mathrm{~cm}$ virtually divided into four quadrants (North, South, West, East) filled with $26^{\circ} \mathrm{C}$ opaque water. Visual cues were placed around the pool. The platform was located at the center of the North-East quadrant. On the first day of training mice learn to find the visible dark platform, if they are not able to find the platform during a time span of $1 \mathrm{~min}$, they were placed on top of the platform. On the second, third, and forth experimental day the dark visible platform was replaced by an invisible see-through one. Animals were introduced to the MWM from different quadrants with 1 min time to find the invisible platform. The time latency to reach the platform as well as swim speed and the time spent in each quadrant was measured ${ }^{91}$.

Western blot analysis. Mice were sacrificed by anesthetics overdose given by intraperitoneal (IP) injection. Brains were dissected, mouse hippocampi were taken and snap frozen in liquid nitrogen. Hippocampal sections were dissociated with a pastel and incubated in RIPA buffer $(25 \mathrm{mM}$ Tris $\mathrm{HCl} \mathrm{pH} \mathrm{7.6,150} \mathrm{mM} \mathrm{NaCl}$, $1 \%$ NP-40, $1 \%$ sodium deoxycholate, and $0.1 \%$ SDS) for $2 \mathrm{~h}$ at $4{ }^{\circ} \mathrm{C}$. Lysates were centrifuged at $4{ }^{\circ} \mathrm{C}, 10,000 \mathrm{~g}$ for $5 \mathrm{~min}$, and supernatants were kept at $-80^{\circ} \mathrm{C}$ until use. Protein concentration was determined by bicinchoninic acid protein assay kit (BCA, Pierce) and the absorbance was subsequently measured with NanoDrop spectrophotometer. Samples were denaturized for $10 \mathrm{~min}$ at $70{ }^{\circ} \mathrm{C}$ in Laemmli buffer $(2 \times)$, separated on a $10 \%$ TGX gel at $200 \mathrm{~V}$ for 30-40 min (Biorad) and transferred onto a nitrocellulose membrane (Biorad) for $1 \mathrm{~h}$ at 100 V. Protein transfer was verified using Rouge Ponceau and membranes were subsequently rinsed with TBS-T before blocking with $5 \%$ non-fat dry milk for $1 \mathrm{~h}$, at room temperature (RT). Membranes were incubated in appropriate primary antibodies (anti-KCC2 1:3000 (Merck), anti-NKCC1 1:1000 (Abcam), anti- $\beta$-tubulin 1:10,000 (Neuromics), anti-human APP W02 1:2000 (Merk), total APP anti-C-terminus 1:4000 (Sigma Aldrich), anti-soluble APP clone 22C11 1:500 (Merck), anti-GABA ${ }_{B}$ R 1:500 (Sigma Aldrich), anti-GABA $A_{A} \alpha 1$ 1:1000 (Alomone labs), anti-GABA ${ }_{A}$ R $\alpha 2$ 1:1000 (Abcam), anti-GABA $\mathrm{R} \alpha 3$ 1:1000 (Alomone labs), anti-GABA ${ }_{\mathrm{A}} \mathrm{R}$ 5 1:1000 (Alomone labs), anti-GluA1 1:500 (Merck), anti-GluA2 1:1000 (Merck), anti-GluN2A 1:250 (Merck), anti-GluN2B 1:500 (BD Biosciences), anti-GAD65/67 1:1000 (Abcam)) at $4{ }^{\circ} \mathrm{C}$, overnight. On the second day membranes were rinsed in TBS-T and incubated in adequate secondary antibodies (anti-rabbit (Dako/P448) or anti-mouse (Cell signaling) 1:10,000) for $1 \mathrm{~h}$, RT. Before protein detection with ECL (BioRad) membranes were rinsed with TBS-T $(3 \times 10 \mathrm{~min})$ and revealed on hyper film (GE Healthcare). Quantification of protein levels was performed by densitometry and reported to $\beta$-tubulin expression.

Organotypic brain slice culture. For the determination of soluble mouse APP, mice were rapidly sacrificed, and their brains taken and transferred into ice-cold artificial cerebrospinal fluid (ACSF) composed of $126 \mathrm{mM} \mathrm{NaCl}, 3 \mathrm{mM} \mathrm{KCl}, 2.4 \mathrm{mM} \mathrm{CaCl}_{2}, 1.3 \mathrm{mM} \mathrm{MgCl}_{2}, 1.24 \mathrm{mM} \mathrm{NaH}_{2} \mathrm{PO}_{4}, 26 \mathrm{mM} \mathrm{NaHCO}_{3}$, and $10 \mathrm{mM}$ glucose (bubbled with $95 \% \mathrm{O}_{2}-5 \% \mathrm{CO}_{2} \%$ ). After the removal of the cerebellum and frontal cortex, brains were mounted onto a vibratome and sagittal sections of $150 \mu \mathrm{m}$ were cut in ice-cold ACSF to obtain the dorsal hippocampus. Brain slices were transferred into a 12 -well plate (four brain slices for each animal in one well) filled with ACSF and kept at $37{ }^{\circ} \mathrm{C}$ and $5 \% \mathrm{CO}_{2}$. After an incubation period of $2 \mathrm{~h}$, media were collected and kept at $-80^{\circ} \mathrm{C}$ until use.

Electrochemiluminescence (ECLIA) and enzyme-linked immunosorbent assay (ELISA). Animals were sacrificed at desirable age by anesthetics overdose, hippocampi were taken and kept frozen at $-80^{\circ} \mathrm{C}$ until use. Electrochemiluminescence (ECLIA) assays for human-specific soluble APP (sAPP $\alpha / s A P P \beta$; Mesoscale) and amyloid beta $\left(\mathrm{A} \beta_{40} / \mathrm{A} \beta_{42}\right.$; Mesoscale) as well as enzyme-linked immunosorbent assay (ELISA) for Glutamate (Abcam) and GABA (Cloud-Clone Corporation) were performed according to the manufacturer's protocol. Hippocampal tissue was lysed in RIPA buffer, the extracted supernatant was used for quantification and normalized to protein content.

Electrophysiology. Brain slice preparation. Animals were sacrificed by cervical dislocation, their brains harvested and transferred to ice-cold ACSF composed of $126 \mathrm{mM} \mathrm{NaCl}, 3 \mathrm{mM} \mathrm{KCl}, 2.4 \mathrm{mM} \mathrm{CaCl}, 1.3 \mathrm{mM}$ 
$\mathrm{MgCl}_{2}, 1.24 \mathrm{mM} \mathrm{NaH}_{2} \mathrm{PO}_{4}, 26 \mathrm{mM} \mathrm{NaHCO}_{3}$, and $10 \mathrm{mM}$ glucose (bubbled with $95 \% \mathrm{O}_{2}-5 \% \mathrm{CO}_{2} \%$ ). After the removal of the cerebellum and frontal cortex brains were mounted onto vibratome and sagittal sections of $350 \mu \mathrm{m}$ were cut in ice-cold ACSF to obtain the dorsal hippocampus. Brain slices were acclimatized in oxygenated $\mathrm{ACSF}$ at $32^{\circ} \mathrm{C}$ for at least $1 \mathrm{~h}$ before use.

Field potential recordings. Brain slices were transferred to the recording chamber while continuously being perfused by oxygenated ACSF $(2 \mathrm{ml} / \mathrm{min})$ at $30^{\circ} \mathrm{C}$. Field excitatory postsynaptic potentials (fEPSPs) were evoked through a bipolar stimulating electrode which was placed in the Schaffer collaterals (SCs) and recorded by AxoClamp 2B amplifier through a glass electrode which was back-filled with $2 \mathrm{M} \mathrm{NaCl}$ and placed in the CA1 region (stratum radiatum). Stimuli consisted of $100 \mu$ s pulses of constant currents with intensity adjusted to produce $35 \%$ of the maximum response every minute. Responses were stabilized for 30 to $60 \mathrm{~min}$ ( 1 stimulation/min) after placement of the electrodes. All responses were digitalized using Digidata 1322A (Axon Instruments, USA) and recorded on a computer using WinLTP software ${ }^{93}$. Long-term potentiation (LTP) was induced by applying a theta-burst stimulation (TBS) consisting of four trains of five pulses $(100 \mathrm{~Hz})$ separated by an interburst interval of $200 \mathrm{~ms}$. fEPSP responses were normalized to the pre-TBS baseline and defined as $100 \%$. Paired-pulse facilitation was calculated as the ratio of the slope from the second to the first response for each paired stimulation event. In a separate experiment baclofen $(100 \mu \mathrm{M})$ was after LTP induction. Additionally, fEPSP were recorded in response to TBS stimulation at $20 \mathrm{~Hz}$. Basal recordings were obtained during $30 \mathrm{~min}$ with $1 \mathrm{stimulation} / \mathrm{min}$. Brain slices were stimulated by one train of five pulses $(20 \mathrm{~Hz})$ separated by an interval of $50 \mathrm{~ms}$. In a separate experiment brain slices were additionally constantly perfused with $500 \mu \mathrm{M}$ CGP36216 (Tocris).

EEG electrode implantation. Mice were anesthetized with isoflurane (5\% induction, $2 \%$ maintenance in $\mathrm{O}_{2}$ ) along with their heads immobilized in a stereotactic frame for implantation of electroencephalography (EEG) electrodes. After exposure of the skull small burr holes were made: one for the epidural ground/reference electrode above the right frontal cortex, one for the tripolar electrode above the right hippocampus and three for the placement of anchor screws (two left and one right parietal). The epidural electrode was custom-made by attaching an insulated copper wire to an anchor screw (Invivo1, $1.75 \mathrm{~mm}$ ). The tripolar depth electrode was custom made by twisting 3 polyimide-coated stainless-steel wires (California fine wire, $70 \mu \mathrm{m}$ bare diameter). A distance of $600 \mu \mathrm{m}$ was maintained between the longest (granule cell layer, DG) and middle (pyramidal cell layer, CA1) electrode tips; $400 \mu \mathrm{m}$ was maintained between the middle (CA1) and shortest (cortex) tips. This depth electrode was implanted stereotactically (coordinates $-2.0 \mathrm{~mm}$ anteroposterior (AP); $+1.5 \mathrm{~mm}$ mediolateral (ML) relative to bregma; $\pm 2.0 \mathrm{~mm}$ dorsoventral (DV) relative to dura). Electrophysiological feedback was used during surgery to position the tip of the longest electrode in the granule cell layer of the dentate gyrus upper blade.

EEG recordings. Starting one week after implantation mice were connected to the EEG setup which consists of a head stage with a unity gain preamplifier, a 6-channel cable, a commutator, and an amplifier $(512 \times)$. A data acquisition card (NI, USB-6256, 16-bit, $20 \mathrm{mV}$ input range) digitized signals at $2 \mathrm{kHz}$ and stored them on a PC for offline analysis (Matlab, Mathworks). All recordings were performed under controlled conditions with a $12 \mathrm{~h}$ light-dark cycle with lights on between 6AM and 6PM. Room temperature ranged from $20-24^{\circ} \mathrm{C}$ with $40-60 \%$ humidity. During the EEG recording, mice were housed separately in transparent cages (to allow social interactions) where they were able to move freely. EEG recordings were performed during lights-on periods (12AM-5PM). Recordings were analyzed and epileptiform spikes were manually annotated. Baclofen (Tocris) was administered by intraperitoneal injection $(1 \mathrm{mg} / \mathrm{kg}$ in $0.9 \% \mathrm{w} / \mathrm{v} \mathrm{NaCl})$.

Histology. Antibody staining on paraffin sections. After sedation animals were perfused transcardially with ice-cold PBS and afterwards with cold 4\% paraformaldehyde (PFA). Brains were collected and kept in $4 \%$ PFA for at least 2 days at $4{ }^{\circ} \mathrm{C}$ before paraffin embedding. Sagittal brain sections $(5 \mu \mathrm{m})$ were obtained using a microtome. For histological analysis, only brain sections exhibiting an intact hippocampal morphology were used. Before staining slices were de-paraffinized (xylene, $2 \times 10 \mathrm{~min}$ ) and rehydrated using descending (100-90-70$50 \%)$ ethanol (EtOH) concentrations. Antigen retrieval was performed at $95{ }^{\circ} \mathrm{C}$ for $10 \mathrm{~min}$ using citrate buffer. Cooled down brain sections were blocked with PBS and normal goat serum (NGS) for 20 min, RT. Primary antibody (anti-cleaved caspase-3 1:200, Cell signaling) was diluted accordingly in PBS and 2\% bovine serum (BSA) and applied onto brain sections for $2 \mathrm{~h}$, RT. After washing with PBS-T $(2 \times 5 \mathrm{~min})$ and PBS $(1 \times 5 \mathrm{~min}), \alpha$-rabbit 1:200 (Vector Laboratories) secondary biotinylated antibody diluted in PBS/NGS was applied for 45 min, RT. Brain sections were incubated using Vectastain ABC kit (45 min, RT) and afterwards washed and incubated in 3,3'-Diaminobenzidine (DAB) for maximum $5 \mathrm{~min}$ at RT, the intensity of the reaction was observed using a light microscope. After washing the slides in $\mathrm{H}_{2} \mathrm{O}$ for $10 \mathrm{~min}$, samples were dehydrated with ascending EtOH concentrations (50-70-90-100\%) and incubated in xylene (10 min) for final fixation. Dry slides were mounted with DPX and left to dry overnight. Slides were scanned using Slide Scanner SCN400 (Leica) and analyzed with Image Scope software.

Nissl staining. Paraffin embedded brain sections were dewaxed, rehydrated (see previous section), and incubated for $20 \mathrm{~min}$ in $0.1 \%$ Cresyl violet solution. After differentiation of the staining in $70 \% \mathrm{EtOH}$ brain slices were dehydrated in $\mathrm{EtOH}$, mounted with DPX, and dried overnight. Slides were scanned using the slice scanner SCN400 (Leica) and viewed with Image Scope software. The number of neurons in the CA1 region of the hippocampus was assessed using ImageJ software and cross referenced to the digital Allen Mouse Brain Atlas. For each hippocampus sections of the CA1 area measuring $300 \times 300 \mu \mathrm{m}$ were analyzed. Neurons with round and 
palely stained nuclei were considered as viable, while shrunken and dark stained cells were considered as dead. Data were expressed as the number of surviving neurons per CA1 section.

Statistical analysis. Statistical analysis of all data points collected in experiments mentioned in this study was performed using GraphPad Prism 7.03. For each set of experiments "n" represents one brain slice (LTP, short-term facilitation, histology) or one animal (behavior, EEG, western blot, ECLIA/ELISA). Normal distribution of data point was assessed using D’Agostino-Pearson omnibus normality test. For comparison of two groups with normal distributions and equal variances, two-tailed unpaired t-test was performed while for the comparison of two groups with unequal variances a two-tailed unpaired t-test with Welch's correction was applied. To compare two or more groups with normal distributions and equal variances, a two-way analysis of variance (ANOVA) with Sidak's post-hoc test was performed. For the assessment of anxiety, the time spent in the center (OF), time spent in the light zone (LDT), the distance travelled (LDT), and the time spent in open arms (EPM) raw data was transformed into a data set expressed as the percentage of the raw data using the Excel PERCENTRANK function. For LTP quantification, experimental groups were compared in the last 15 min of the experiment, when LTP was stable. Experimental datasets are expressed as a mean \pm standard error of mean (SEM). Statistical significance was fixed to $\mathrm{P} \leq 0.05\left({ }^{\star} \mathrm{P} \leq 0.05,{ }^{* *} \mathrm{P} \leq 0.01,{ }^{* * *} \mathrm{P} \leq 0.001,{ }^{* * * *} \mathrm{P} \leq 0.0001\right)$.

Received: 5 May 2021; Accepted: 13 August 2021

Published online: 02 September 2021

\section{References}

1. Gralle, M. \& Ferreira, S. T. Structure and functions of the human amyloid precursor protein: the whole is more than the sum of its parts. Prog. Neurobiol. 82, 11-32 (2007).

2. Kang, J. et al. The precursor of Alzheimer's disease amyloid A4 protein resembles a cell-surface receptor. Nature 325, 733-736 (1987).

3. De Strooper, B., Iwatsubo, T. \& Wolfe, M. S. Presenilins and $\gamma$-secretase: structure, function, and role in Alzheimer Disease. Cold Spring Harb. Perspect. Med. 2, a006304 (2012).

4. Haass, C. Initiation and propagation of neurodegeneration. Nat. Med. 16, 1201-1204 (2010).

5. Kuhn, P.-H. et al. ADAM10 is the physiologically relevant, constitutive $\alpha$-secretase of the amyloid precursor protein in primary neurons. EMBO J. 29, 3020-3032 (2010).

6. Busche, M. A. \& Konnerth, A. Impairments of neural circuit function in Alzheimer's disease. Philos. Trans. R. Soc Lond. Ser. B Biol. Sci. 371, 20150429 (2016).

7. Hsia, A. Y. et al. Plaque-independent disruption of neural circuits in Alzheimer's disease mouse models. Proc. Natl. Acad. Sci. U. S. A. 96, 3228-3233 (1999).

8. Egan, M. F. et al. Randomized trial of verubecestat for mild-to-moderate Alzheimer's disease. N. Engl. J. Med. 378, 1691-1703 (2018).

9. Honig, L. S. et al. Trial of solanezumab for mild dementia due to Alzheimer's disease. N. Engl. J. Med. 378, 321-330 (2018).

10. Salloway, S., Sperling, R. \& Brashear, H. R. Phase 3 trials of solanezumab and bapineuzumab for Alzheimer's disease. N. Engl. J. Med. 370, 1459-1460 (2014).

11. Alzforum (n.d.). Aducanumab. Retrieved April 25, 2021 https://www.alzforum.org/therapeutics/aducanumab (2020).

12. Sevigny, J. et al. The antibody aducanumab reduces A $\beta$ plaques in Alzheimer's disease. Nature 537, 50-56 (2016).

13. Wang, Z. et al. Human brain-derived A $\beta$ oligomers bind to synapses and disrupt synaptic activity in a manner that requires APP. J. Neurosci. 37, 11947-11966 (2017).

14. Menéndez, M. Down syndrome, Alzheimer's disease and seizures. Brain Dev. 27, 246-252 (2005).

15. Deidda, G. et al. Reversing excitatory GABAAR signaling restores synaptic plasticity and memory in a mouse model of Down syndrome. Nat. Med. 21, 318-326 (2015).

16. Palop, J. J. et al. Aberrant excitatory neuronal activity and compensatory remodeling of inhibitory hippocampal circuits in mouse models of Alzheimer's disease. Neuron 55, 697-711 (2007).

17. Born, H. A. et al. Genetic suppression of transgenic APP rescues Hypersynchronous network activity in a mouse model of Alzeimer's disease. J. Neurosci. 34, 3826-3840 (2014).

18. Johnson, E. C. B. et al. Behavioral and neural network abnormalities in human APP transgenic mice resemble those of App knockin mice and are modulated by familial Alzheimer's disease mutations but not by inhibition of BACE1. Mol. Neurodegener. 15, 53 (2020).

19. Freude, K. K., Penjwini, M., Davis, J. L., LaFerla, F. M. \& Blurton-Jones, M. Soluble amyloid precursor protein induces rapid neural differentiation of human embryonic stem cells. J. Biol. Chem. 286, 24264-24274 (2011).

20. Hu, Y. et al. Role of cystatin C in amyloid precursor protein-induced proliferation of neural stem/progenitor cells ${ }^{*}$. J. Biol. Chem. 288, 18853-18862 (2013).

21. Hoe, H.-S. et al. Interaction of reelin with amyloid precursor protein promotes neurite outgrowth. J. Neurosci. 29, 7459-7473 (2009).

22. Priller, C. et al. Synapse formation and function is modulated by the amyloid precursor protein. J. Neurosci. 26, 7212-7221 (2006).

23. Kohli, B. M. et al. Interactome of the amyloid precursor protein APP in brain reveals a protein network involved in synaptic vesicle turnover and a close association with Synaptotagmin-1. J. Proteome Res. 11, 4075-4090 (2012).

24. Fanutza, T., Del Prete, D., Ford, M. J., Castillo, P. E. \& D’Adamio, L. APP and APLP2 interact with the synaptic release machinery and facilitate transmitter release at hippocampal synapses. Elife 4, e09743 (2015).

25. Yao, W., Tambini, M. D., Liu, X. \& D’Adamio, L. Tuning of Glutamate, But Not GABA, Release by an Intrasynaptic Vesicle APP Domain Whose Function Can Be Modulated by $\beta$ - or $\alpha$-Secretase Cleavage. J. Neurosci. 39, 6992-7005 (2019).

26. Dawson, G. R. et al. Age-related cognitive deficits, impaired long-term potentiation and reduction in synaptic marker density in mice lacking the beta-amyloid precursor protein. Neuroscience 90, 1-13 (1999).

27. Seabrook, G. R. et al. Mechanisms contributing to the deficits in hippocampal synaptic plasticity in mice lacking amyloid precursor protein. Neuropharmacology 38, 349-359 (1999).

28. Ozawa, S., Kamiya, H. \& Tsuzuki, K. Glutamate receptors in the mammalian central nervous system. Prog. Neurobiol. 54, 581-618 (1998).

29. Dingledine, R., Borges, K., Bowie, D. \& Traynelis, S. F. The glutamate receptor ion channels. Pharmacol. Rev. 51, 7-61 (1999). 
30. Cousins, S. L. et al. APLP1 and APLP2, members of the APP family of proteins, behave similarly to APP in that they associate with NMDA receptors and enhance NMDA receptor surface expression. J. Neurochem. 133, 879-885 (2015).

31. Cousins, S. L. et al. Amyloid precursor protein 695 associates with assembled NR2A- and NR2B-containing NMDA receptors to result in the enhancement of their cell surface delivery. J. Neurochem. 111, 1501-1513 (2009).

32. Hoe, H.-S. et al. The effects of amyloid precursor protein on postsynaptic composition and activity. J. Biol. Chem. 284, 8495-8506 (2009).

33. Chang, E. H. et al. AMPA receptor downscaling at the onset of Alzheimer's disease pathology in double knockin mice. Proc. Natl. Acad. Sci. U. S. A. 103, 3410-3415 (2006).

34. Rivera, C. et al. The K+/Cl- co-transporter KCC2 renders GABA hyperpolarizing during neuronal maturation. Nature 397, 251-255 (1999).

35. Sun, D. \& Murali, S. G. Na+-K+-2Cl- cotransporter in immature cortical neurons: A role in intracellular Cl- regulation. J. Neurophysiol. 81, 1939-1948 (1999).

36. Ben-Ari, Y. The GABA excitatory/inhibitory developmental sequence: A personal journey. Neuroscience 279, 187-219 (2014).

37. Doshina, A. et al. Cortical cells reveal APP as a new player in the regulation of GABAergic neurotransmission. Sci. Rep. 7, 1-14 (2017).

38. Chen, M. et al. APP modulates KCC2 expression and function in hippocampal GABAergic inhibition. Elife 6, 1-26 (2017).

39. Hawrot, E. et al. Demonstration of a tandem pair of complement protein modules in GABA(B) receptor 1a. FEBS Lett. 432, 103-108 (1998).

40. Rice, H. C. et al. Contribution of GABAergic interneurons to amyloid- $\beta$ plaque pathology in an APP knock-in mouse model. Mol. Neurodegener. 15, $3(2020)$

41. Schwenk, J. et al. Modular composition and dynamics of native GABAB receptors identified by high-resolution proteomics. Nat. Neurosci. 19, 233-242 (2016).

42. Dinamarca, M. C. et al. Complex formation of APP with GABA(B) receptors links axonal trafficking to amyloidogenic processing. Nat. Commun. 10, 1331 (2019).

43. Rice, H. C. et al. Secreted amyloid-b precursor protein functions as a GABA B R1a ligand to modulate synaptic transmission. Science (80-) 363, eaao4827 (2019).

44. Mucke, L. et al. High-level neuronal expression of abeta 1-42 in wild-type human amyloid protein precursor transgenic mice: synaptotoxicity without plaque formation. J. Neurosci. 20, 4050-4058 (2000).

45. Mockett, B. G., Richter, M., Abraham, W. C. \& Müller, U. C. Therapeutic Potential of Secreted Amyloid Precursor Protein APPsa. Front. Mol. Neurosci. 10, 30 (2017).

46. Ooigawa, H. et al. The fate of Nissl-stained dark neurons following traumatic brain injury in rats: Difference between neocortex and hippocampus regarding survival rate. Acta Neuropathol. 112, 471-481 (2006).

47. Verret, L. et al. Inhibitory interneuron deficit links altered network activity and cognitive dysfunction in Alzheimer model. Cell 149, 708-721 (2012)

48. Palop, J. J. \& Mucke, L. Network abnormalities and interneuron dysfunction in Alzheimer disease. Nat. Rev. Neurosci. 17, 777-792 (2016).

49. Fritschy, J.-M. \& Panzanelli, P. GABAA receptors and plasticity of inhibitory neurotransmission in the central nervous system. Eur. J. Neurosci. 39, 1845-1865 (2014).

50. Sperk, G., Schwarzer, C., Tsunashima, K., Fuchs, K. \& Sieghart, W. GABA(A) receptor subunits in the rat hippocampus I: Immunocytochemical distribution of 13 subunits. Neuroscience 80, 987-1000 (1997).

51. Malenka, R. C. \& Nicoll, R. A. Silent synapses speak up. Neuron 19, 473-476 (1997).

52. Voigt, T., Opitz, T. \& de Lima, A. D. Activation of early silent synapses by spontaneous synchronous network activity limits the range of neocortical connections. J. Neurosci. 25, 4605-4615 (2005).

53. Traynelis, S. F. et al. Glutamate receptor ion channels: structure, regulation, and function. Pharmacol. Rev. 62, 405-496 (2010).

54. Ong, J. et al. Short communication CGP 36216 is a selective antagonist at GABA B presynaptic receptors in rat brain. Eur. J. Pharmacol. 415, 191-195 (2001).

55. Dai, M.-H., Zheng, H., Zeng, L.-D. \& Zhang, Y. The genes associated with early-onset Alzheimer's disease. Oncotarget 9, 1513215143 (2018).

56. Busche, M. A. \& Konnerth, A. Neuronal hyperactivity-A key defect in Alzheimer's disease?. BioEssays 37, 624-632 (2015).

57. Simón, A. M. et al. Overexpression of wild-type human APP in mice causes cognitive deficits and pathological features unrelated to A $\beta$ levels. Neurobiol. Dis. 33, 369-378 (2009).

58. Thonberg, H. et al. Mutation screening of patients with Alzheimer disease identifies APP locus duplication in a Swedish patient. BMC Res. Notes 4, 476 (2011).

59. Hooli, B. V. et al. Role of common and rare APP DNA sequence variants in Alzheimer disease. Neurology 78, 1250-1257 (2012).

60. Cabrejo, L. et al. Phenotype associated with APP duplication in five families. Brain 129, 2966-2976 (2006).

61. Menendez, M. Down syndrome, Alzheimer's disease and seizures. Brain Dev. 27, 246-252 (2005).

62. Pan, H. et al. Amyloid $\beta$ is not the major factor accounting for impaired adult hippocampal neurogenesis in mice overexpressing amyloid precursor protein. Stem Cell Rep. 7, 707-718 (2016).

63. Puzzo, D. et al. Picomolar amyloid-beta positively modulates synaptic plasticity and memory in hippocampus. J. Neurosci. 28, 14537-14545 (2008).

64. Anni, D. et al. A $\beta 1-16$ controls synaptic vesicle pools at excitatory synapses via cholinergic modulation of synapsin phosphorylation. Cell. Mol. Life Sci. 78, 4973-4992 (2021).

65. Pousinha, P. A. et al. The amyloid precursor protein C-terminal domain alters CA1 neuron firing, modifying hippocampus oscillations and impairing spatial memory encoding. Cell Rep. 29, 317-331.e5 (2019).

66. Levenga, J. et al. Tau pathology induces loss of GABAergic interneurons leading to altered synaptic plasticity and behavioral impairments. Acta Neuropathol. Commun. 1, 34 (2013).

67. Sieghart, W. \& Sperk, G. Subunit composition, distribution and function of GABA(A) receptor subtypes. Curr. Top. Med. Chem. 2, 795-816 (2002).

68. Whiting, P. J. P. J. GABA-A receptor subtypes in the brain: A paradigm for CNS drug discovery?. Drug Discov. Today 8, 445-450 (2003).

69. Limon, A., Reyes-Ruiz, J. M. \& Miledi, R. Loss of functional GABA(A) receptors in the Alzheimer diseased brain. Proc. Natl. Acad. Sci. U. S. A. 109, 10071-10076 (2012).

70. Opsomer, R. et al. Amyloid precursor protein (APP) controls the expression of the transcriptional activator neuronal PAS domain protein 4 (NPAS4) and synaptic GABA release. eNeuro 7, 1-18 (2020).

71. Collinson, N. et al. Enhanced learning and memory and altered GABAergic synaptic transmission in mice lacking the $\alpha 5$ subunit of the GABA A receptor. J. Neurosci. 22, 5572-5580 (2002).

72. Sur, C., Fresu, L., Howell, O., McKernan, R. M. \& Atack, J. R. Autoradiographic localization of alpha5 subunit-containing GABAA receptors in rat brain. Brain Res. 822, 265-270 (1999).

73. Löw, K. et al. Molecular and neuronal substrate for the selective attenuation of anxiety. Science 290, 131-134 (2000).

74. Kaupmann, K. et al. GABA(B)-receptor subtypes assemble into functional heteromeric complexes. Nature 396, 683-687 (1998). 
75. Guetg, N. et al. The GABAB1a isoform mediates heterosynaptic depression at hippocampal mossy fiber synapses. J. Neurosci. 29, 1414-1423 (2009).

76. Chalifoux, J. R. \& Carter, A. G. GABAB receptors modulate NMDA receptor calcium signals in dendritic spines. Neuron 66, 101-113 (2010).

77. Guetg, N. et al. NMDA receptor-dependent GABAB receptor internalization via CaMKII phosphorylation of serine 867 in GABAB1. Proc. Natl. Acad. Sci. U. S. A. 107, 13924-13929 (2010).

78. Terunuma, M., Vargas, K. J., Wilkins, M. E., Ramírez, O. A. \& Jaureguiberry-bravo, M. Prolonged activation of NMDA receptors promotes dephosphorylation and alters postendocytic sorting of GABA B receptors. PNAS 107, 13918-13923 (2010).

79. Al Abed, A. S. et al. Age-related impairment of declarative memory: linking memorization of temporal associations to GluN2B redistribution in dorsal CA1. Aging Cell 19, e13243 (2020).

80. Migaud, M. et al. Enhanced long-term potentiation and impaired learning in mice with mutant postsynaptic density-95 protein. Nature 396, 433-439 (1998).

81. Garcia-Alvarez, G. et al. Impaired spatial memory and enhanced long-term potentiation in mice with forebrain-specific ablation of the Stim genes. Front. Behav. Neurosci. 9, 180 (2015).

82. Pineda, V. V. et al. Removal of G(ialpha1) constraints on adenylyl cyclase in the hippocampus enhances LTP and impairs memory formation. Neuron 41, 153-163 (2004).

83. Taylor, C. J. et al. Endogenous secreted amyloid precursor protein-alpha regulates hippocampal NMDA receptor function, longterm potentiation and spatial memory. Neurobiol. Dis. 31, 250-260 (2008).

84. Ring, S. et al. The secreted beta-amyloid precursor protein ectodomain APPs alpha is sufficient to rescue the anatomical, behavioral, and electrophysiological abnormalities of APP-deficient mice. J. Neurosci. 27, 7817-7826 (2007).

85. Larson, J. \& Munkácsy, E. Theta-burst LTP. Brain Res. 1621, 38-50 (2015)

86. Richter, M. C. et al. Distinct in vivo roles of secreted APP ectodomain variants APPsa and APPs $\beta$ in regulation of spine density, synaptic plasticity, and cognition. EMBO J. 37, 2018 (2018).

87. Wang, B. et al. The amyloid precursor protein controls adult hippocampal neurogenesis through GABAergic interneurons. J. Neurosci. 34, 13314-13325 (2014).

88. Lee, K. J. et al. Beta amyloid-independent role of amyloid precursor protein in generation and maintenance of dendritic spines. Neuroscience 169, 344-356 (2010).

89. Kleschevnikov, A. M. et al. Deficits in cognition and synaptic plasticity in a mouse model of Down syndrome ameliorated by GABAB receptor antagonists. J. Neurosci. 32, 9217-9227 (2012).

90. Lepannetier, S. et al. Activation of TRPC1 channel by metabotropic glutamate receptor mGluR5 modulates synaptic plasticity and spatial working memory. Front. Cell. Neurosci. 12, 1-19 (2018).

91. Boucherie, C. et al. Neural progenitor fate decision defects, cortical hypoplasia and behavioral impairment in Celsr1-deficient mice. Mol. Psychiatry 23, 723-734 (2018).

92. Morris, R. Developments of a water-maze procedure for studying spatial learning in the rat. J. Neurosci. Methods 11, 47-60 (1984).

93. Anderson, W. W. \& Collingridge, G. L. Capabilities of the WinLTP data acquisition program extending beyond basic LTP experimental functions. J. Neurosci. Methods 162, 346-356 (2007).

\section{Author contributions}

P.G. conceived the study. P.K.C., R.R., J.N.O. and P.G. designed the experiments. A.K., J.D., N.S., X.Y., F.I., O.S., R.G. and Md.C. performed the experiments. A.K., X.Y., O.S., N.P., N.T. and P.G. analyzed the data. A.K. and P.G. wrote the manuscript text. All authors reviewed the manuscript.

\section{Funding}

This work was supported by the Belgian Fund for Scientific Research (FNRS, Grant EQP U.N011.17 and CDR J.0065.21), the "Fondation pour la Recherche sur la Maladie d'Alzheimer" (SAO/FRA), the Queen Elisabeth Medical Foundation and the Concerted Research Action from the General Direction of Scientific Research of the French Community of Belgium (ARC17/22-083).

\section{Competing interests}

The authors declare no competing interests.

\section{Additional information}

Supplementary Information The online version contains supplementary material available at https://doi.org/ 10.1038/s41598-021-97144-3.

Correspondence and requests for materials should be addressed to P.G.

Reprints and permissions information is available at www.nature.com/reprints.

Publisher's note Springer Nature remains neutral with regard to jurisdictional claims in published maps and institutional affiliations.

(c) (i) Open Access This article is licensed under a Creative Commons Attribution 4.0 International License, which permits use, sharing, adaptation, distribution and reproduction in any medium or format, as long as you give appropriate credit to the original author(s) and the source, provide a link to the Creative Commons licence, and indicate if changes were made. The images or other third party material in this article are included in the article's Creative Commons licence, unless indicated otherwise in a credit line to the material. If material is not included in the article's Creative Commons licence and your intended use is not permitted by statutory regulation or exceeds the permitted use, you will need to obtain permission directly from the copyright holder. To view a copy of this licence, visit http://creativecommons.org/licenses/by/4.0/.

(c) The Author(s) 2021 